ISSN 1996-1073

www.mdpi.com/journal/energies

Article

\title{
Non Breaking Wave Forces at the Front Face of Seawave Slotcone Generators
}

\author{
Mariano Buccino ${ }^{1, *}$, Davide Banfi ${ }^{1}$, Diego Vicinanza ${ }^{2}$, Mario Calabrese ${ }^{1}$, \\ Giuseppe Del Giudice ${ }^{1}$ and Armando Carravetta ${ }^{1}$
}

1 Department of Hydraulic, Geotechnical and Environmental Engineering, University of Naples Federico II, Via Clauio 21, Naples, Italy; E-Mails: davidebanfi@hotmail.com (D.B.); calabres@unina.it (M.C.); Giuseppe.delgiudice@unina.it (G.D.G.); Armando.carravetta@unina.it (A.C.)

2 Department of Civil Engineering, Second University of Naples, Via Roma 29, 81031 Aversa (Caserta), Italy; E-Mail: diego.vicinanza@unina2.it

* Author to whom correspondence should be addressed; E-Mail: buccino@unina.it; Tel.: +39-0817683428; Fax: +39-5938936.

Received: 17 September 2012; in revised form: 1 November 2012 / Accepted: 16 November 2012 / Published: 19 November 2012

\begin{abstract}
The Seawave Slotcone Generator (WAVEnergy SAS, 2003) is a wave energy converter based on the overtopping principle. Although it has been effectively researched during the last decade, no design tool has been supplied to estimate the hydrodynamic loads the waves exert on its front face. In this article a set of well reliable 3D experiments has been re-analyzed, in order to get indications on possible calculation methods. It is shown that the Japanese design tools for monolithic sea dikes may be reasonably adapted to the present case. Finally a new approach is presented, which is based on the so called momentum flux principle; the resulting predictive equation fits the experimental data remarkably well.
\end{abstract}

Keywords: wave energy converters; Seawave Slotcone Generator (SSG); wave forces; physical model tests 


\section{Introduction}

The Seawave Slotcone Generator (SSG, Figure 1) is a Wave Energy Converter (WEC) based on the overtopping principle (see [1]). The wedge of water that climbs the front-face during the up-rush phase is captured in a number of reservoirs (generally two or three) placed on top of each other; thus, the water, on its way back to the sea, passes through a turbine, spinning it and generating electricity. A number of studies [2-4] suggest that the use of multiple reservoirs results in a higher overall efficiency compared to structures which employ a single tank.

Figure 1. Artistic representation of a 3-level SSG (WAVEnergy SAS, 2003).

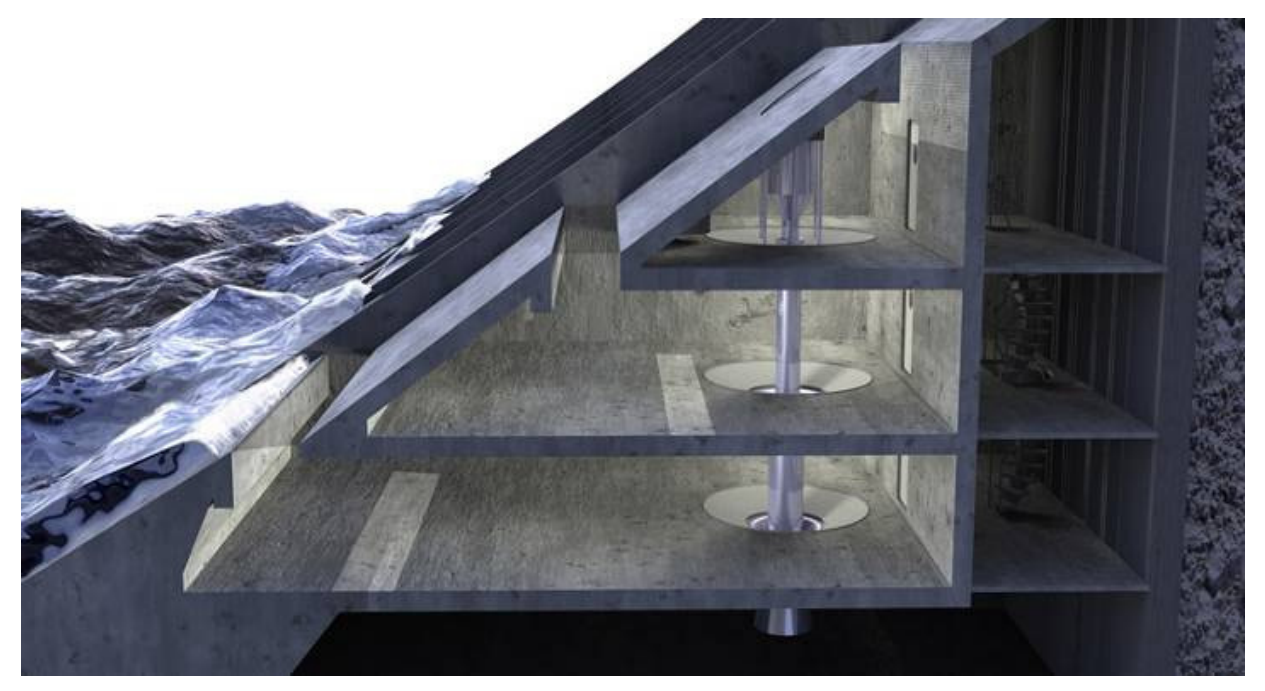

SSG devices have been well researched during the last decade and two pilot plants have been planned to be located along the west Norwegian coasts; one at the isle of Kvitsøy (in the Bokna fjord, not far from Stavanger, Figure 2) and at the other at Svåheia (very close to Kvitsøy). Although these projects have not been realized, they have had however the result of intensifying the research activity. Indeed, the latter has also been encouraged by the fact that both the structure of the device (concrete monolithic dike) and its working principle (run up, overtopping) are well known to researchers in the field of maritime engineering.

Figure 2. The Kvitsøy site.

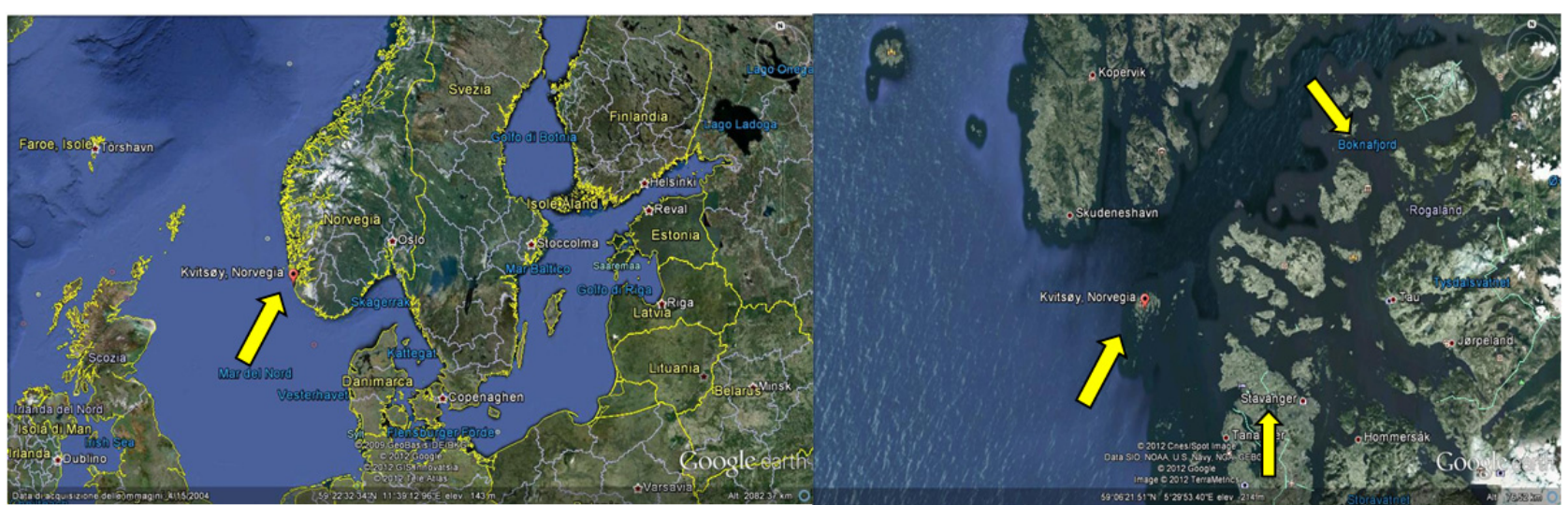


A recent paper published on this journal [5] reviews the fruitful work done so far. Yet, going through the pages of the article, it becomes clear that many design tools have been developed for various aspects of the technology (e.g., for predicting the mean overtopping rate, the hydraulic and overall efficiencies, the wave reflection, etc.), except for the structural response. In fact the tests performed by Vicinanza and Frigaard [6] to estimate the wave loadings acting on the Kvitsøy pilot system did not lead to a real design formula, but only to some order of magnitude indications. However, the authors noted that some of the design tools traditionally employed by coastal engineers could result in significant underpredictions of the pressure peaks.

This lack of knowledge may be central to the future of this technology, because the SSG is by nature exposed to severe seas and the economic impact of the structural design could be so heavy as to discourage investors. In this regard, it is obvious that the want of clear indications and the absence of ad hoc experimental analyses, drive engineers to build by themselves design criteria that will be invariably too safe and expensive. The scope of this paper is to start to fill that gap.

The experiments of Vicinanza and Frigaard are re-analyzed here in order to suggest possible calculation methods. The starting point of our work is the comparison with the Japanese design tools for monolithic sea defense structures. Then a new approach is presented, which proved to work remarkably well with reference to the available data.

\section{Experiments}

The experiments have been carried out at the Department of Civil Engineering of the University of Aalborg, Denmark [6].

\subsection{Tests Description}

The tests have been performed in a basin $15.7 \mathrm{~m}$ long, $8.7 \mathrm{~m}$ wide and $1.5 \mathrm{~m}$ deep provided with 10 independent piston type paddles, capable of generating both long crested (2D) and short crested (3D) waves. Both the SSG and the bathymetry of the site have been reproduced in the tank at a 1:60 length-scale ratio. The SSG device has been located at the top of a steep rocky cliff, inclined 1:1 with respect to the horizontal (Figure 3).

Figure 3. Cross section of the bathymetry.

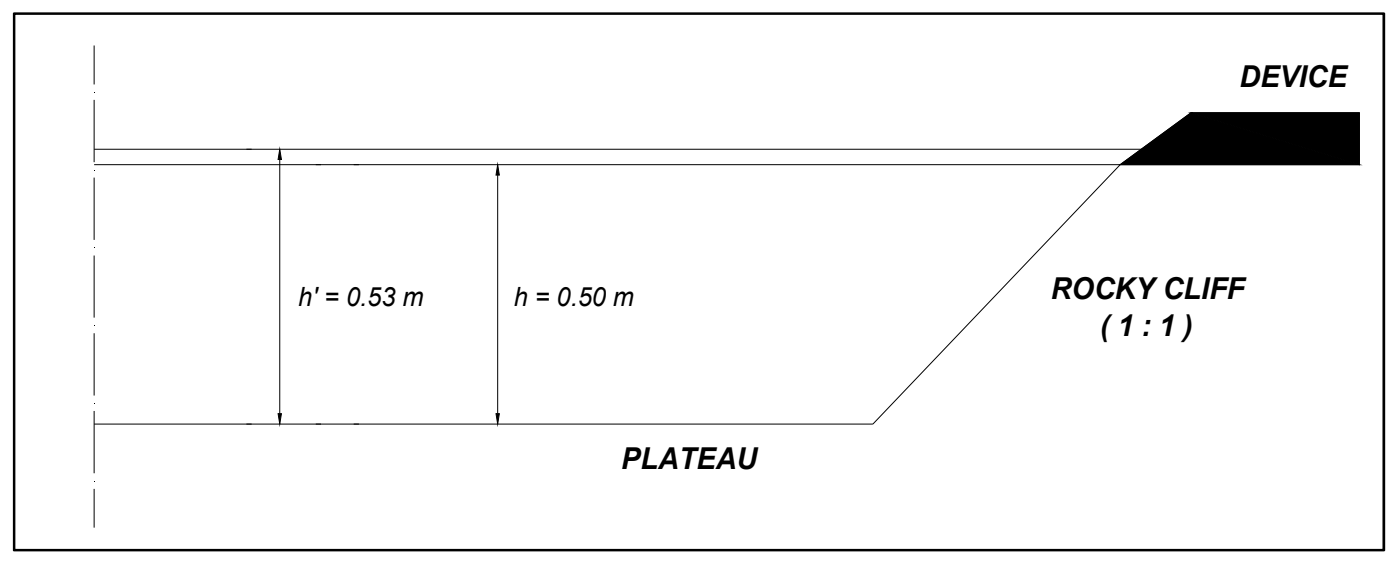


The role of the cliff is enhancing the run-up height; in the following we'll refer to it as "run-up ramp" or "focuser". Seawards of the cliff, the bottom has been kept constant for $5 \mathrm{~m}$, corresponding to $300 \mathrm{~m}$ in the prototype. The SSG model, made of Plexiglass, included three reservoirs and three front plates with a 35 degrees front slope angle (Figure 4).

Figure 4. Sketch of the SSG model (dimensions are in $\mathrm{mm}$ ).

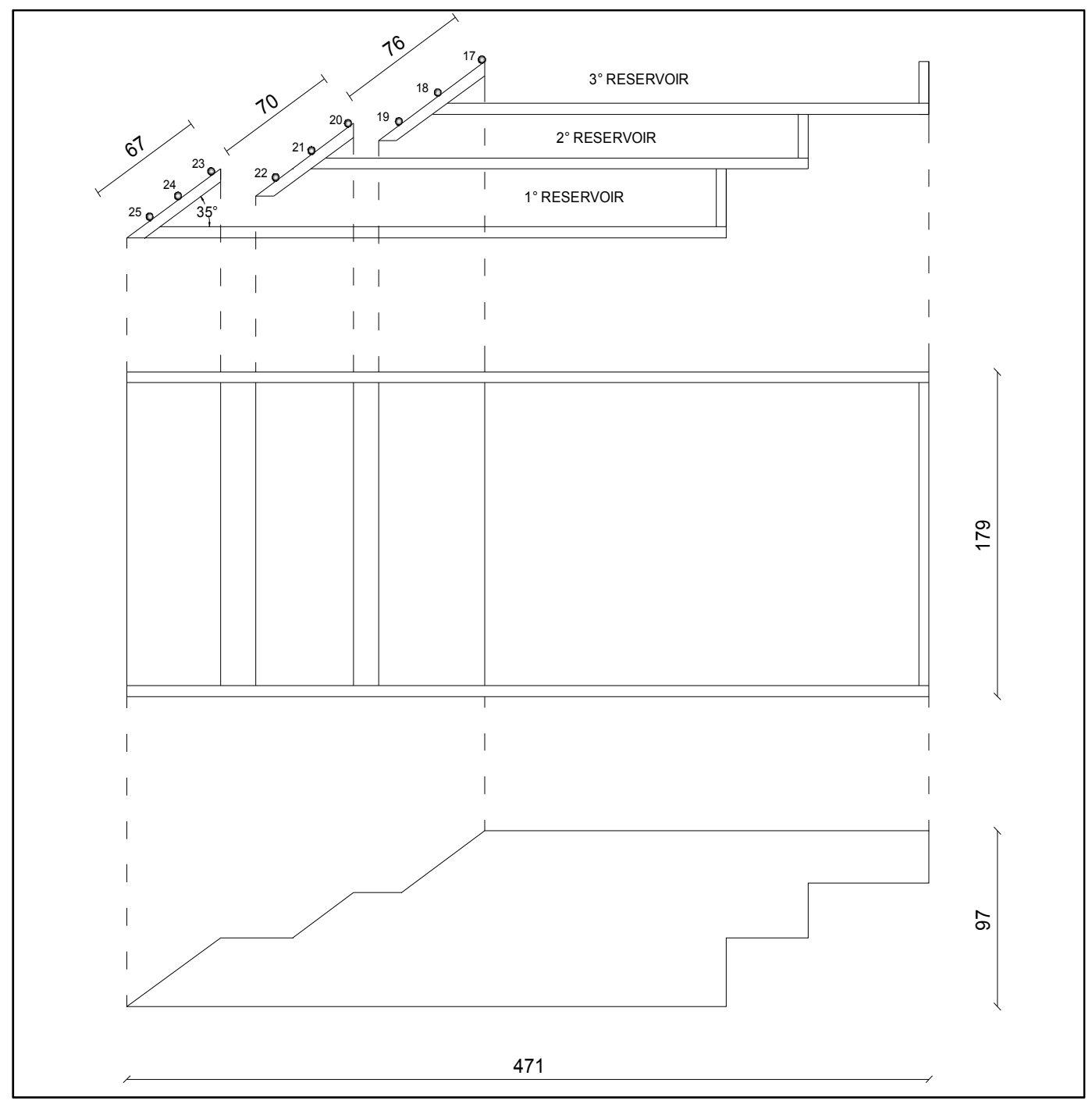

Altogether 32 JONSWAP driven random sea states were run, 16 with long crested waves (2D) and 16 with short crested waves (3D). The spectral significant wave height, $H_{\mathrm{s}}$, varied from $0.042 \mathrm{~m}$ to $0.25 \mathrm{~m}$ and the peak period, $T_{p}$, ranged from $1.03 \mathrm{~s}$ to $2.07 \mathrm{~s}$.

$2 \mathrm{D}$ tests have been conducted using two different water levels at the toe of the cliff $(h)$, and namely $0.53 \mathrm{~m}$ (eight tests) and $0.5 \mathrm{~m}$ (eight tests). The former corresponds to a water depth at the toe of the device $(d)$ equal to $0.03 \mathrm{~m}(1.8 \mathrm{~m}$ in prototype), while the latter leaves the SSG completely exposed (shoreline device, $d=0 \mathrm{~m}$ ). For each array of eight tests, four tests have been carried out with normal waves ("Front waves", $F$ ) and four with oblique waves with an angle of propagation relative to the normal to the structure $\left(\beta_{0}\right)$ equal to 45 degrees ("Side waves", $S$ ). Short crested waves have been generated using a cosine power directional spreading function: 


$$
S\left(\beta ; \beta_{0}\right)=\cos ^{2 n}\left|\beta-\beta_{0}\right| \text { with }-\frac{\pi}{2} \leq\left(\beta-\beta_{0}\right) \leq \frac{\pi}{2}
$$

where $\beta$ is the direction of propagation of the generic Fourier component and $\beta_{0}$ is the mean direction of the waves. $n$ is a spreading index; the larger is $n$, the lower the dispersion of the spectral components. 3D tests have been conducted with a single value of $h$, i.e., $0.53 \mathrm{~m}$. The same array of eight tests used for the long crested waves has been repeated twice with two different values of $n$, namely $n=10$ (small spreading) and $n=4$ (large spreading).

The wave pressures at the structure have been recorded through 14 pressure cells sampled at $200 \mathrm{~Hz}$. Nine of them were located on the front face, three for each plate.

\subsection{Breaker Types and Characteristics of Loadings}

Vicinanza and Frigaard observed that at the front face of the SSG, the waves took the shape of surging breakers, which climbed the structure inducing a massive overtopping. The occurrence of surging breakers, which in fact are non-breaking waves, produces pressures with of a relatively low magnitude (on the order of $H_{\mathrm{s}}$ in the water column) and a slow variation in time. This can be easily observed from Figure 7 of the Vicinanza and Frigaard paper. However, it has been also noted that under oblique wave attacks a part of the wave front violently hit the side wall of the SSG, inducing a rapidly varying intense loading.

\subsection{Model and Scale Effects}

Before performing the analysis, it could be of interest to briefly highlight the possible source(s) of bias between the model results and the prototype reality. As reasoned above, the absence of a real breaking at the front face of the structure produced slowly acting loads, generally termed "pulsating" or "quasi static"; it is generally well accepted that this kind of forces are free of significant scale effects [7]. Obviously, this is true so long as all the phenomena which govern the wave structureinteraction are well reproduced in the model. In the present context, the most relevant interaction mode is obviously wave overtopping. In this regard, it has long been known that a possible source of distortion comes from surface tension effects, which, however, have been recognized to be relevant only for very shallow water depths $(h<0.02 \mathrm{~m})$ and/or for very short periods $(T<0.33 \mathrm{~s})$ [8]. Unfortunately, most recent investigations conducted within the research project CLASH [9], funded by EU, proved model and scale effects on wave overtopping are very hard to avoid, being the mean overtopping discharge in prototype larger than in the model; yet the difference reduces with increasing overtopping rate.

Since in most of present experiments the amount of water overpassing the structure crest was huge, it is expected that the bias to be small; furthermore, as wave loads acting on the wall reduce with increasing overtopping, it can be argued that model results presented below might be slightly conservative compared to the actual prototype conditions.

More significant scale effects are expected to affect the breaking wave pressures at the side walls of the SSG. A number of literature studies have indicated that, for plunging waves, the real wave pressure may be largely overestimated by up to $60 \%$ or more by Froude scaling. An interesting method to evaluate the magnitude of the bias has been recently proposed by Cuomo et al. [10], based on the 
so-called Bagnold number. The features of the wave actions at the side walls are not dealt with in this paper, but represent an intriguing topic to be researched in the future.

Before concluding this discussion, a further aspect deserves to be addressed. As the experiments were conducted in a rectangular basin, the incoming waves may excite the natural oscillation modes of the facility, giving rise to resonance phenomena. This would produce parasitic standing waves in the tank, that may affect the reliability of the results. However the simulated sea-states have very short frequency bands, included between 0.25 and $2 \mathrm{~Hz}$, so that the excited frequencies are short enough to be absorbed by the rubble beach placed at the end of the basin and to be damped out by the friction of the concrete walls of the tank. This reasoning was also supported by the good agreement between the wave spectra generated by the wavemaker and those measured by a set of seven resistive probes spread throughout the basin [6].

\section{Japanese Design Practice for Monolithic Maritime Dikes}

As briefly mentioned before, a possible point of strength of the SSG may be its similitude with structures usually employed in the field of maritime engineering. This property implies a certain degree of "a priori" knowledge about the processes that govern the wave-structure interaction, which might put the SSG technology a step forward compared to other types of WEC.

As an example, the formula for calculating the mean overtopping rate at the various reservoirs [11] has the same structure as that commonly used for the rubble mound breakwaters [12] and the procedure for evaluating the efficiency of the device includes an algorithm to estimate the "wave by wave" overtopping discharge, which has been originally suggested for vertical breakwaters [13].

As far as the structural response is concerned, the reference is of course that of the monolithic maritime dikes, including vertical face breakwaters [Figure 5(a)], sloping top caissons [Figure 5(b)] and trapezoidal walls [Figure 5(c)].

Figure 5. Examples of monolithic maritime dikes: (a) Vertical breakwater. (b) Sloping top caisson. (c) Trapezoidal wall.

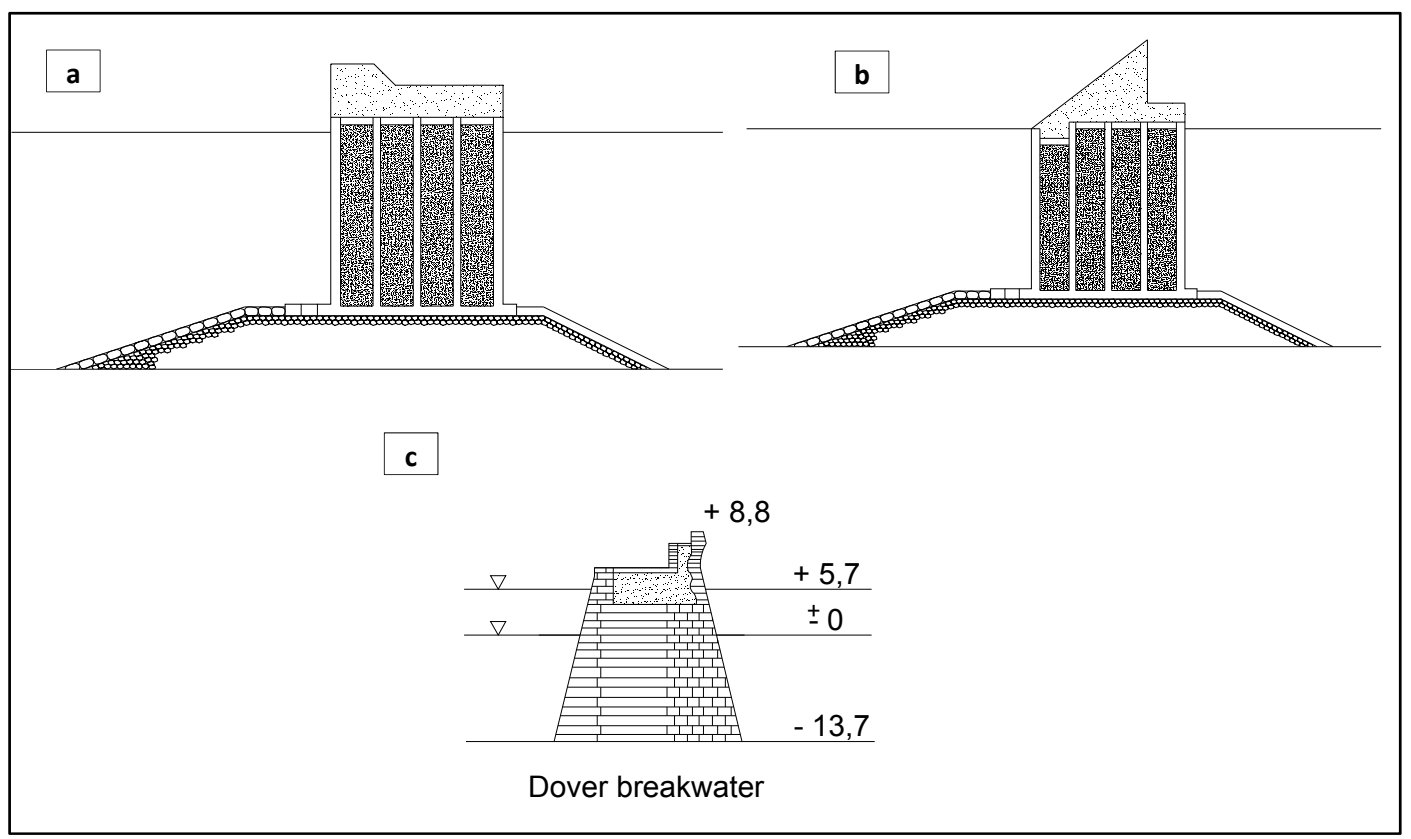


In this paper, particular attention has been drawn to the formulae of the Japanese design practice; this because they are calibrated to work on structures having two features in common with the SSG, namely:

1. a water depth at their toe relatively small;

2. a low crest, allowing for a massive overtopping under the design wave conditions.

Although the methods employed in the following are widely known, a synthetic review is provided in the paragraphs below, both for sake of clarity and to facilitate practical applications.

\subsection{Vertical Face Breakwaters: the Formulae of Hiroi and Goda}

During the design of the Otaru Port breakwater (1912 through 1917) Hiroi conducted in-situ measurements of wave pressures by means of a spring-type instrument. Assimilating the pressure exerted by the waves to that of a jet impinging a plane surface, the author came to the formula:

$$
P=1.5 \rho g H
$$

where $\rho$ is the water density, $g$ is the gravity acceleration and $H$ is the design wave height. The wave pressure $P$ is assumed to act uniformly up to the minimum between the crest of the structure and $1.25 H$ (Figure 6).

Figure 6. Definition sketch for the Hiroi formula.

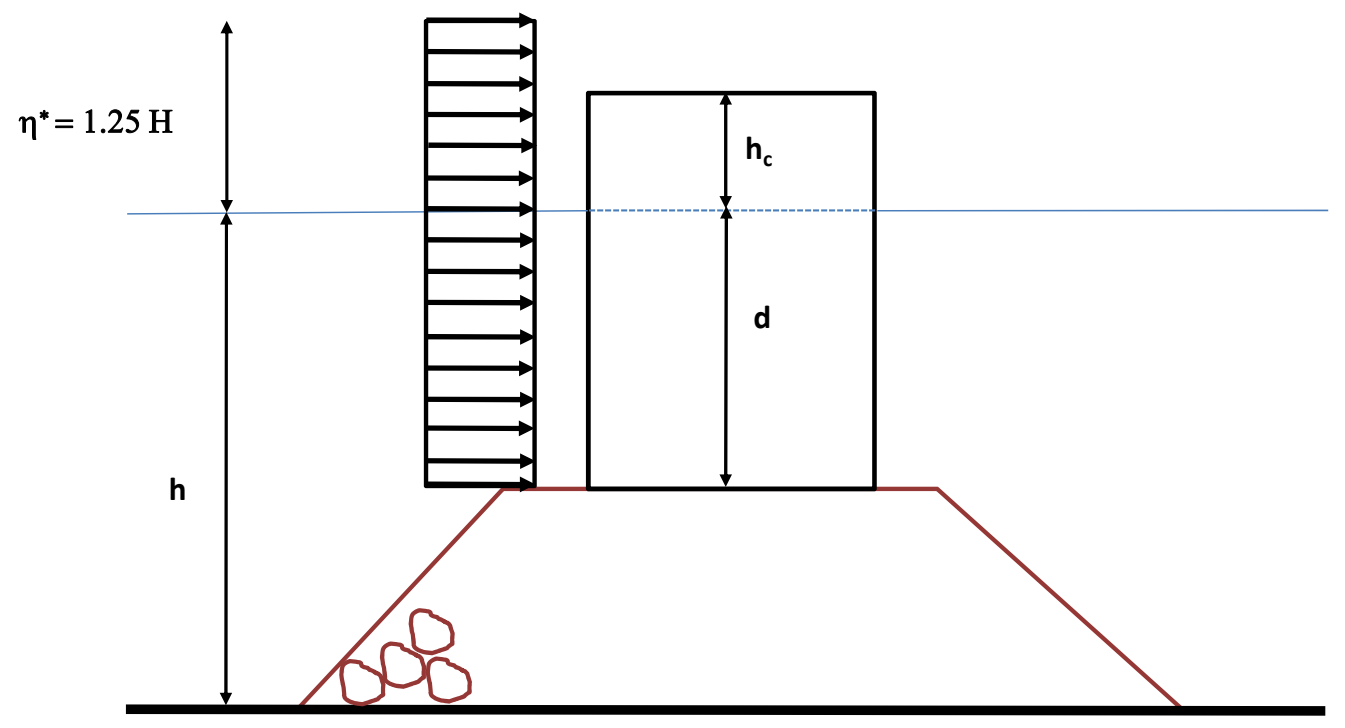

Despite the fact that the Hiroi formula is "apparently intended for calculating the pressure caused by breaking waves" [14], it has been however considered, both in virtue of its simplicity and because of the similitude with an impinging jet, physically appropriate to the case of the SSG.

In 1973 Goda proposed his worldwide-known formula, based on the results of the theoretical and experimental investigations the author conducted between the late $60 \mathrm{~s}$ and the early $70 \mathrm{~s}$. One of the most immediate advantages of the Goda method is that it holds for all the wave conditions, i.e., for both standing and breaking waves. As shown in Figure 7, the pressure distribution under the wave crest is generally bi-trapeizoidal, with a zero at the run-up height. The latter is calculated as: 


$$
\eta^{*}=0.75\left(1+\cos \beta_{0}\right) H
$$

in which $\beta_{0}$, as stated above, is the angle of the wave propagation relative to the normal to the breakwater.

At the mean water level, the wave pressure $p_{1}$ is assumed to be linear in the wave height, although the author noted that "the relative pressure intensity varies with the increase in the relative wave height to a certain extent..." [14]. The expression of $p_{1}$ is:

$$
p_{1}=0.5 \rho g\left(1+\cos \beta_{0}\right)\left(\alpha_{1}+\alpha_{2} \cos ^{2} \beta_{0}\right)
$$

where the parameter $\alpha_{1}$ depends only on the water depth to wavelength ratio $h / L$ :

$$
\alpha_{1}=0.6+0.5\left(\frac{\frac{4 \pi h}{L}}{\operatorname{senh} \frac{4 \pi h}{L}}\right)^{2}
$$

and increases from 0.5 in deep water $(h / L \geq 0.5)$ to 1.1 in shallow waters $(h / L \leq 0.05)$.

The coefficient $\alpha_{2}$ accounts partially for the effects of impulsive loadings and vanishes in the absence of a rubble mound foundation. Its original expression given by Goda was successively modified by Takahashi et al. [15], with the purpose of improving the performance of the formula under plunging breaker conditions.

The wave pressure at the bottom, $p_{2}$, is calculated using the transfer function of the linear waves:

$$
p_{2}=\frac{p_{1}}{\cosh (k h)}
$$

so that the pressure exerted at the toe of the structure, $p_{3}$, can be calculated by linear interpolation.

Figure 7. Definition sketch for the Goda formula.

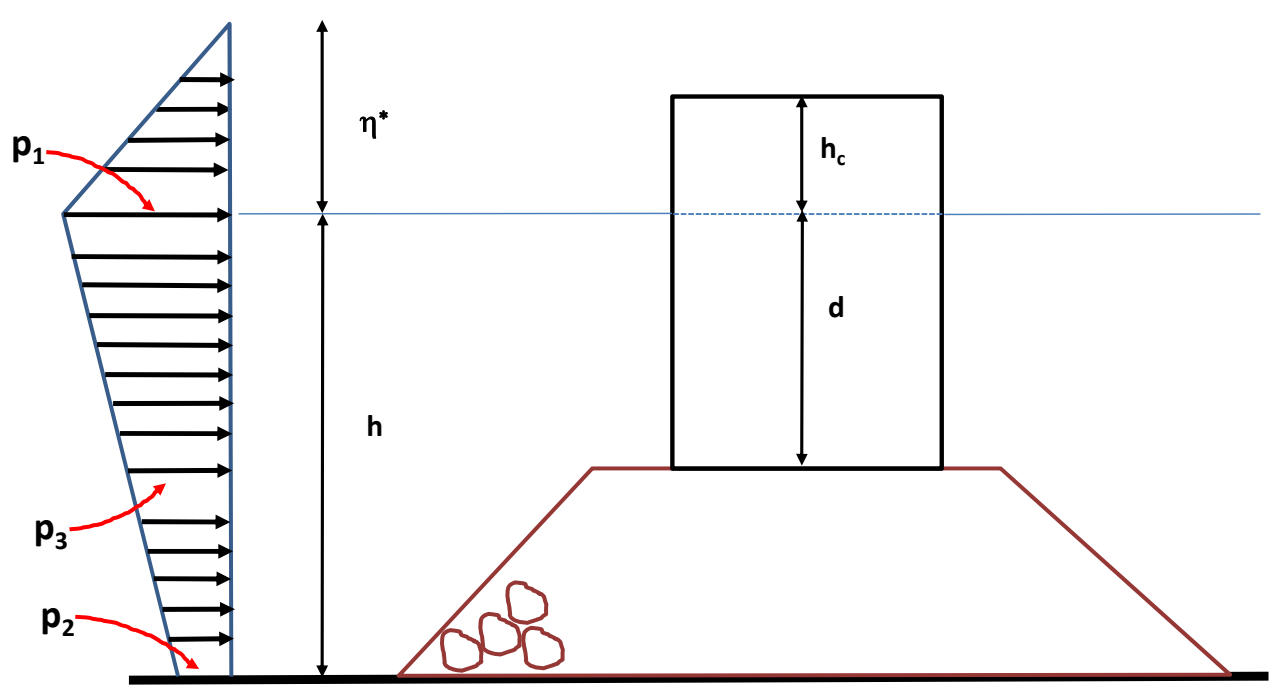




\subsection{Sloping Top Caissons}

When the breakwaters have to face very rough seas, their upper part may be inclined to reduce the horizontal thrust; in addition, the vertical downwards component of the wave force exerted on the sloping part tends to compensate for the uplift force at the breakwater basement, with the result of improving the resistance against overturning. As noted by Takahashi et al. [16], the first sloping top breakwater was constructed in 1906 to defend the Port of Naples (Italy); in Japan the demand for such structures had been growing for some years in the mid-90s, requiring the development of ad-hoc procedures for their design.

The starting point of the Japanese approach to the sloping top caissons is the similitude with the hydrodynamic thrust exerted by a jet of fluid over an inclined plane surface (Figure 8). As mentioned above, the same criterion had inspired the Hiroi formula.

If we indicate with $M_{F}$ the momentum flux of the incoming jet, then, under the hypothesis that after the collision with the slope the velocity of fluid is exclusively tangential to the structure, one gets:

$$
F_{P}=M_{F} \sin \vartheta
$$

in which $\vartheta$ is the angle of the front face to the horizontal.

Figure 8. A fluid jet hitting an inclined wall.

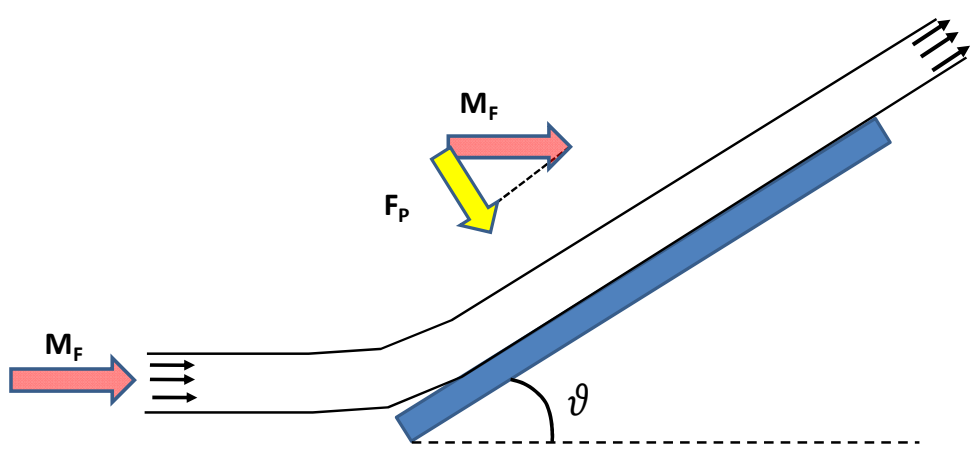

In the method by Morihira and Kunita [17], the momentum flux comes from the Goda's pressure distribution (Figure 9) so that $M_{F}$ can be calculated integrating the loadings (along $\mathrm{z}$ ) from the lower tip of the sloping part $\left(d_{c}\right)$ to the crest of the breakwater $\left(h_{c}\right)$ :

$$
M_{F}=F_{1}=\int_{d c}^{h c} p_{G o d a} d z
$$

Takahashi et al. [16] performed a number of regular wave experiments and found out that the method above led to an underestimation of the forces for small waves and an overprediction of the forces for high waves. Hence the authors proposed the introduction of an uniform correction factor $\lambda_{\mathrm{SL}}$ to be applied to the Goda model in the sloping part of the breakwater. That is:

$$
M_{F}=\lambda_{S L} F_{1}
$$


Figure 9. Definition sketch for the method of Morihira and Kunita.

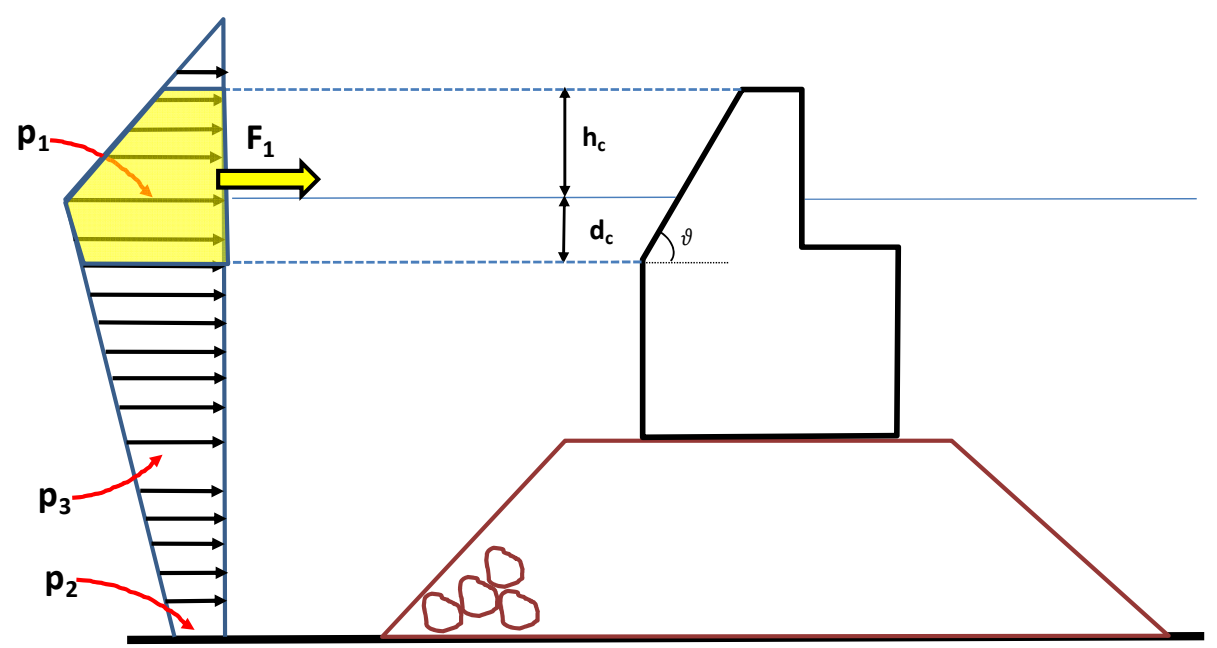

The expression of $\lambda_{S L}$ is:

$$
\lambda_{S L}=\min \left\{\max \left\{1.0 ;-23 \frac{H}{L} \frac{1}{\tan ^{2} \vartheta}+0.46 \frac{1}{\tan ^{2} \vartheta}+\frac{1}{\sin ^{2} \vartheta}\right\} ; \frac{1}{\sin ^{2} \vartheta}\right\}
$$

where $H / L$ is the wave steepness. Note that the authors proposed a different coefficient, $\lambda_{V}$, for the upright face of the structure (below $d_{c}$ ).

\subsection{Trapezoidal Walls}

Tanimoto and Kimura [18] performed a series of laboratory experiments to investigate the magnitude and the distribution of the wave loadings acting on a trapezoidal caisson (Figure 10). The authors came to the conclusion that the Goda model could be simply rotated on the outer face of the breakwater. The experiments also demonstrated that the uplift wave pressure on the caisson bottom is reduced due to the upward water particle velocity enhanced by the slope.

Figure 10. The method of Tanimoto and Kimura.

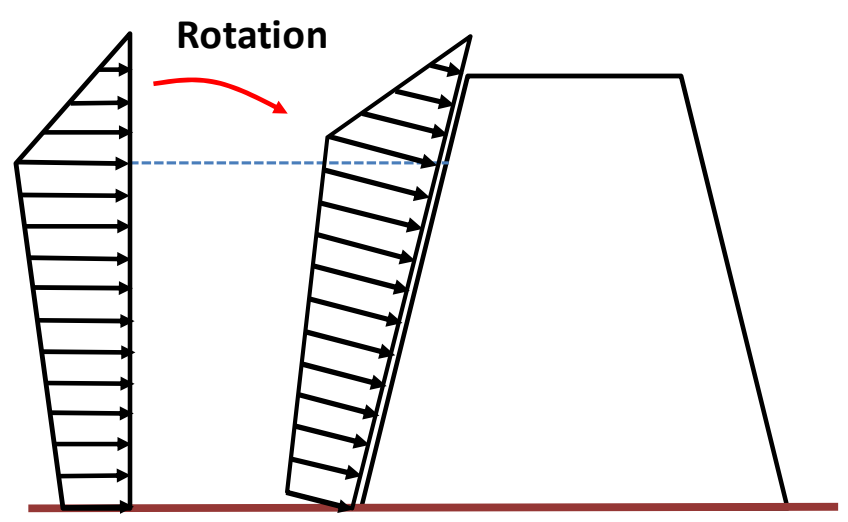

Note that the Tanimoto and Kimura approach leads to values of wave force well larger than those predicted by the Morihira and Kunita method discussed in the previous paragraph. This because the 
Goda's pressure distribution is assumed to be normal to the wall (instead to be horizontal); in addition it is integrated along the outer face of the structure (instead of its vertical projection, Figure 9).

\subsection{Selection of Wave Parameters}

The experiments used to carry out the design tools presented above, employed mostly regular waves; hence the problem arises of how applying the formulae to real sea states. The approach used in the modern Japanese practice, say from the late 60s [19], is that of assimilating a random sequence of waves to a series of regular waves, assuming that the prediction methods are valid "wave by wave". Moreover the principle of breakwater design is essentially deterministic: the structure should withstand the greatest force expected in its service life, which would be exerted (on the statistical average [14]) by the highest wave among a train of random waves corresponding to the design condition. In other words, the maximum wave force acting onto the structure, say $F_{\max }$, has to be calculated by inserting in the design formulae the maximum wave height of the design storm, $H_{\max }$, and its period $T_{\max }$. Being aware of the stochastic nature of these quantities, Goda highlighted their numeric evaluation could be achieved but in a conventional way. Thus, for waves which are stable on the sea bottom (non-breaking waves) he proposed:

$$
\left\{\begin{array}{c}
H_{\max }=1.8 H_{S} \\
T_{\max }=T_{S}
\end{array}\right.
$$

being $H_{s}$ and $T_{s}$ the significant wave height and period respectively. The definition of $H_{\max }$ corresponds to the average of the 1/250th highest waves in a narrow banded random sea state and for this reason it is often indicated also as $H_{1 / 250}$. Consequently, in laboratory and practical engineering applications, the maximum wave force $F_{\max }$ is generally intended as the average of the highest $1 / 250$ th peaks of force in a given random sequence $\left(F_{1 / 250}\right)$. For breakwaters located in shallow waters Goda [19] provided a method to calculate the maximum wave height taking into account the effects of the random wave breaking.

As far as the Hiroi formula, which dates back to the 1920s, is concerned, Japanese engineers were used to applying it employing $H_{s}$ and, as stated by Goda [14], "the formula had not betrayed their trust in its reliability".

\section{Application to SSG}

\subsection{Definition of the Maximum Wave Force $F_{1 / 250}$}

In this study the time histories of the wave pressures at the different transducers were not available. Thus the maximum wave force $F_{1 / 250}$ has been conservatively calculated by integrating the values of the maximum pressures $p_{1 / 250}$ along the front face of the structure. This definition is cautious because, due to the obliquity of the wall, the pressure signals at the different locations are not in phase. However it should be noted that under non-breaking wave conditions the variation of loadings in the time is quite slow and accordingly the phase lags are expected to be relatively small. 


\subsection{How the Prediction Formulae Are Used}

In the following the Tanimoto and Kimura approach for trapezoidal walls is used. The ensemble "SSG + ramp" has been assimilated to a sloping structure and the Goda and Hiroi pressure distributions have been rotated perpendicularly to them (Figure 10). As far as the Goda method is concerned, it should be highlighted that no rubble mound foundation is supposed to exist; consequently the coefficient $\alpha_{2}$ in Equation (4) is always zero.

Consistently with the Japanese practice, the significant wave height $H_{\mathrm{s}}$ has been used to calculate the wave pressure with the Hiroi formula, whereas $H_{1 / 250}=1.8 H_{s}$ has been employed for Goda. As far as the wave period is concerned, the peak period $T_{p}$ has been used instead of $T_{s}$. This because in practical applications, engineers have generally direct information on $T_{p}$, whereas $T_{s}$ is derived from the former by the introduction of an empirical coefficient; the latter is close to 1 and varies within a given range (Goda suggested 0.90-0.95). Since the choice of such a coefficient represents a source of uncertainty, it seemed more convenient to perform the comparison using directly $T_{p}$.

Vicinanza and Frigaard [6] showed that the method of Takahashi et al. [16] for sloping top caissons led to an underestimation of the maximum wave pressures by up to $50 \%$. Hence in this study it will be used in a heuristic manner. Basically, after rotating the Goda distribution on the front face of the SSG, the pressures are multiplied by the factor $\lambda_{S L}$ of Equation (10). Moreover, in the calculation of this coefficient it has been assumed that the effect of the wave steepness on loadings is best represented by the significant wave steepness $H_{s} / L_{p}$ rather than $H_{1 / 250} / L_{p}$. In fact the latter leads to values too big, which reduce the resulting force dramatically.

\section{Results for Long Crested Waves}

\subsection{Goda and Takahashi et al.}

In general neither the simple Goda formula nor the use of the Takahashi et al. correction [16] lead to predict properly the magnitude of the measured pressures $p_{1 / 250}$. This is displayed in Figures 11 and 12, which show the data are rather scattered around the line of perfect agreement, with a relative error reaching and surpassing $50 \%$.

Figure 11. Measured $p_{1 / 250}$ vs. predictions of the Goda formula. Left panel: Front waves; right panel: side waves. Data in $\mathrm{kN} / \mathrm{m}^{2}$.
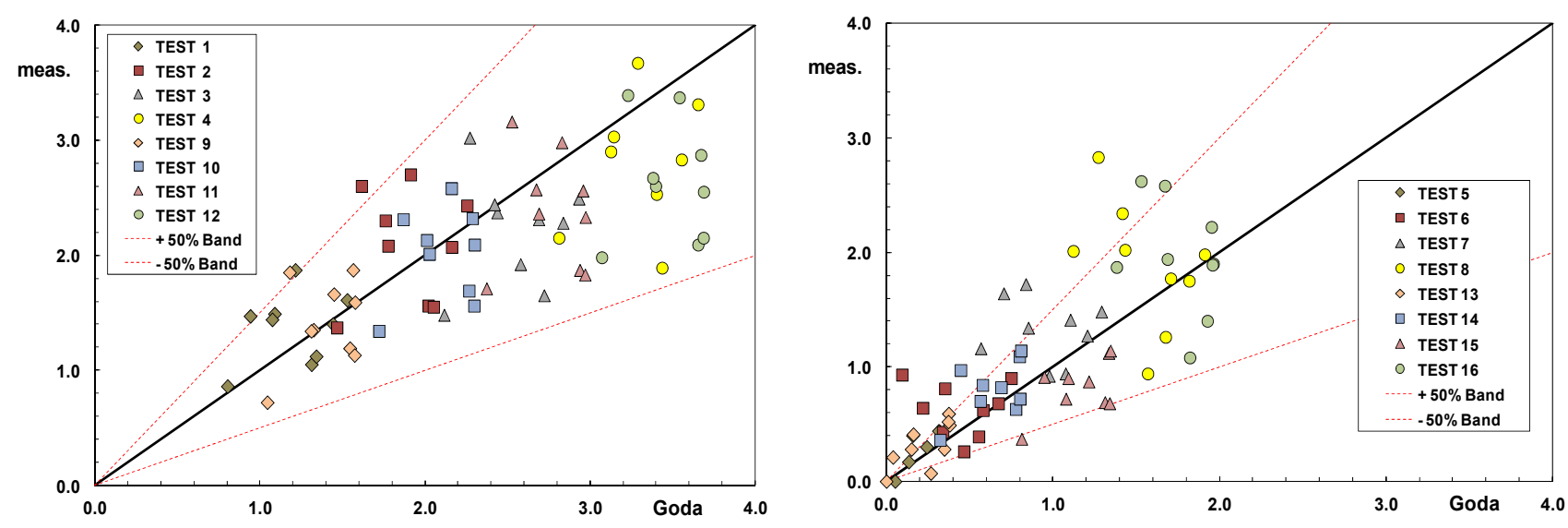
Figure 12. Effect of Takahashi et al. correction [Equation (10)]. Left panel: Front waves; low panel: right waves. Data in $\mathrm{kN} / \mathrm{m}^{2}$.
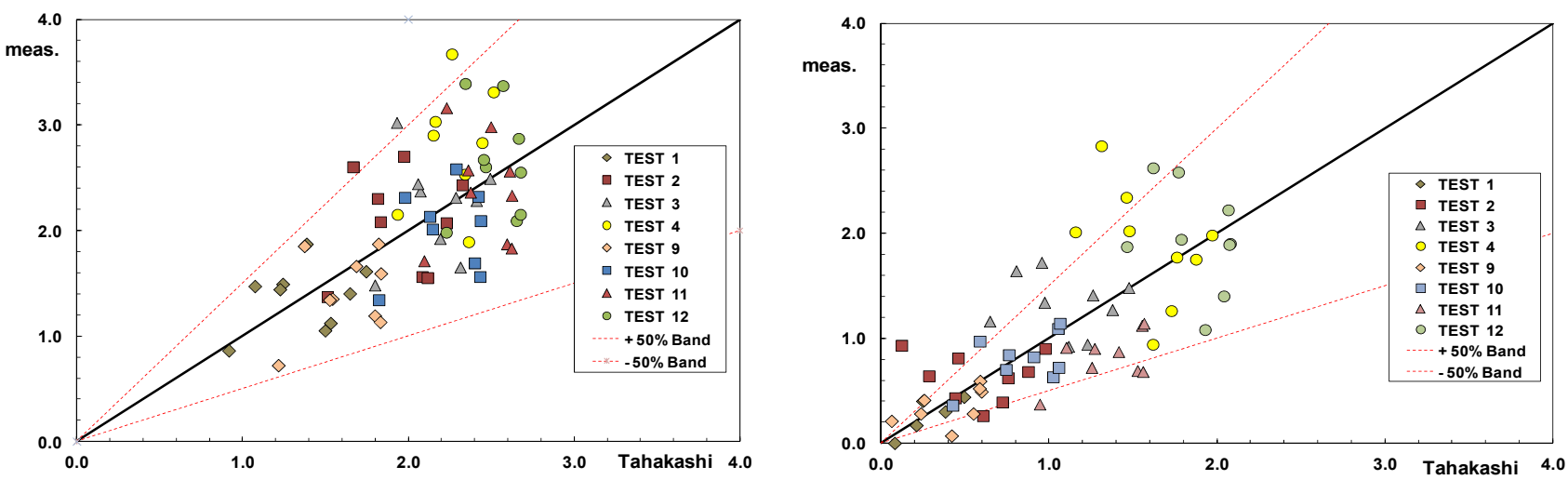

Yet, a deeper insight into the results reveals that, for any given wave attack, both formulae return a reasonable estimate of the mean pressure along the wall $\left(p_{m 250}\right)$ and consequently of total thrust acting on the front face of the SSG. From Figure 13 it is clear the relative error on $p_{m 250}$ is generally less than $20 \%$, which may be considered acceptable from an engineering point of view. It is of interest that with the adjustments proposed in this paper, the Takahashi et al. method does not produce the severe underestimations reported by Vicinanza and Frigaard [6].

Figure 13. Comparison between measured and predicted values of the mean pressures along the wall. In abscissa the test code.

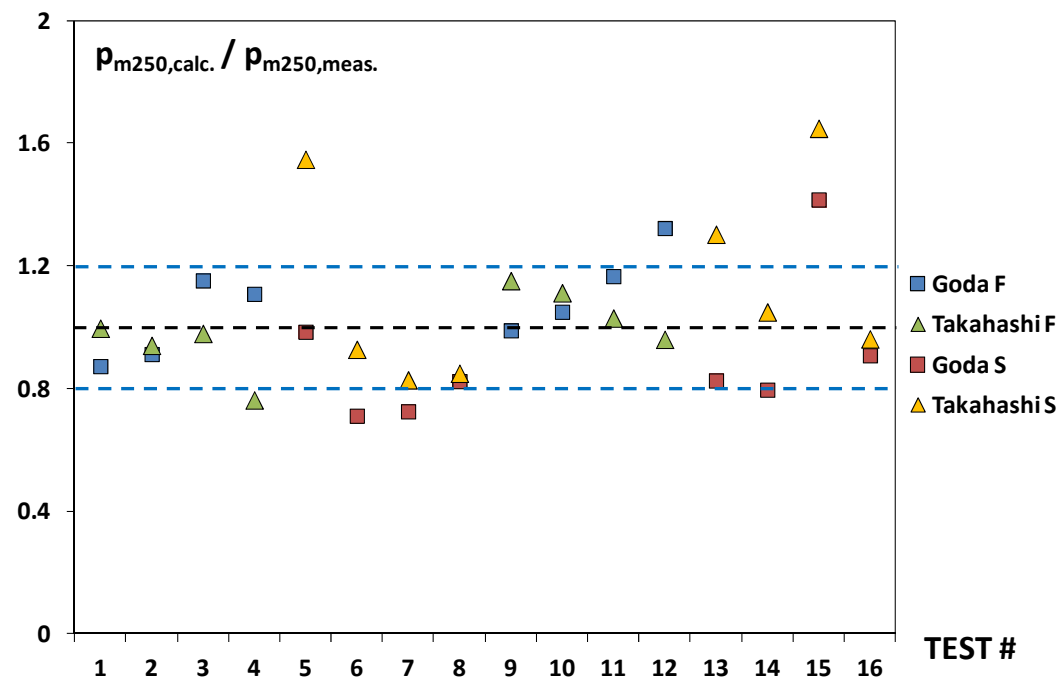

Figure 14 indicates that the overturning moment about the shoreward toe (heel) of the structure is also reasonably predicted by the formulae. Note all the values are negative, meaning that the moments are opposing to the overturning of the SSG. This is due to the fact that the front face of the structure is inclined more than $45^{\circ}$ to the vertical, so that the vertical component of the wave force, which has a stabilizing effect, prevails over the horizontal one.

From the foregoing discussion one may come to the conclusion that despite an unsatisfactory estimate of the local values of the pressures, the Goda and Takahashi et al. methods can acceptably 
predict both the value of the total wave thrust and that of its arm. This is a remarkable result, since SSG is a rigid structure, the failure of which does not depend on the spatial distribution of wave loadings, but only on their resultant.

Figure 14. Measured vs. predicted torques at the structure heel. Left panel: Goda model; right panel: effect of Takahashi et al. correction.
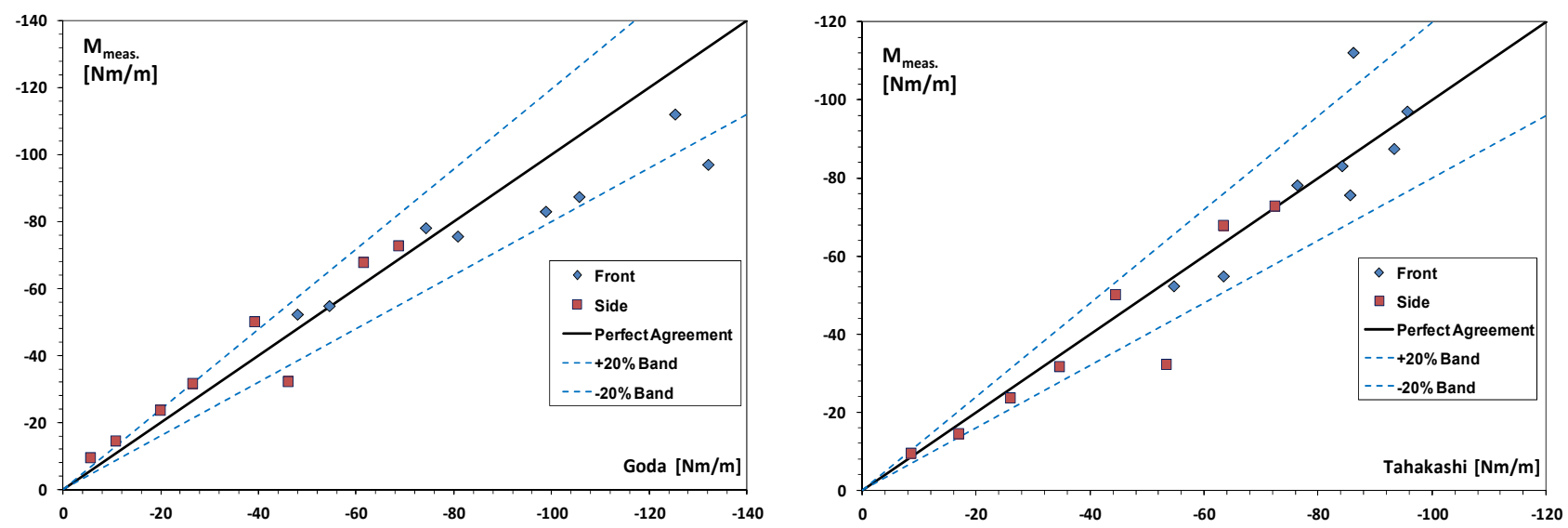

However, the formulae seem to suffer from some lack of fit, which can be best discussed with the aid of the Figure 15. Here, the non dimensional values of the measured mean pressure, $p_{m 250} / \gamma H_{s}$, are plotted versus the wave height to depth ratio $H_{s} / h$. The points are divided into a number of groups depending on the local wave steepness, $H_{s} / L_{p}$. The parameter $H_{s} / h$ has been selected to favor the comparison with the findings of Takahashi et al. [16], who employed that index as starting point of their analysis.

Figure 15. Non dimensional values of the mean pressure as function of the wave height to depth ratio.

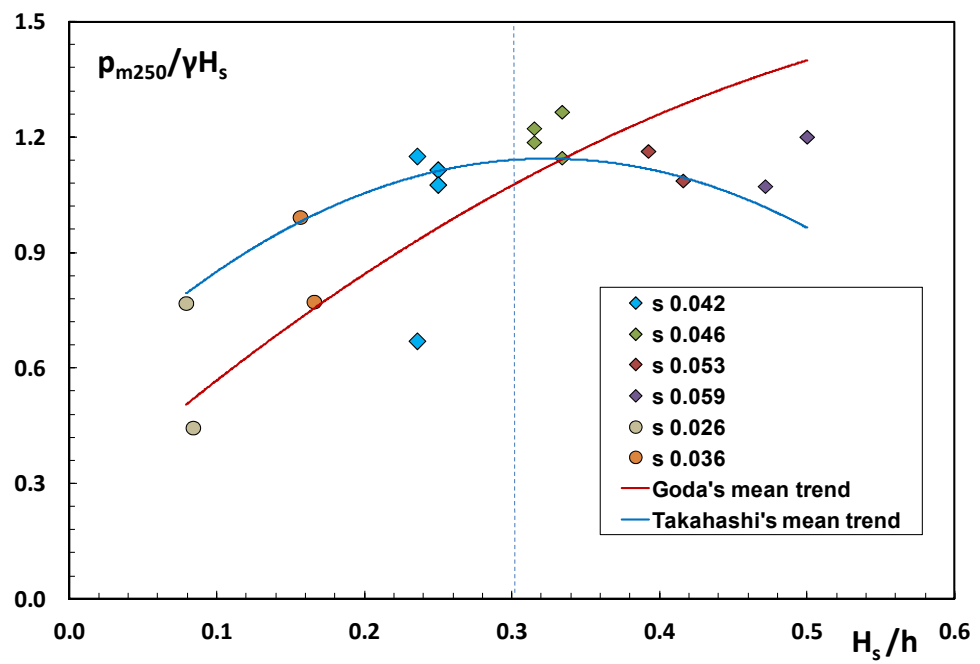

The solid curves in the graph represent the mean trends of the formulae of Goda (red curve) and Takahashi et al. (blue curve). They have been drawn fitting the predicted values of $p_{m 250} / \gamma H_{s}$ with polynomials of different orders, up to get the maximum determination index $R^{2}$. 
Examining the figure, we note the experimental data exhibit an increasing trend, for $H_{s} / h \leq 0.3$, followed by a slightly decreasing one. On the contrary the Goda formula has a monotonic shape which tends to underpredict data with low $H_{s} / h$ (apart from a single outlier circled in the graph) and to overpredict data with high $H_{s} / h$. The threshold between underestimates and overestimates seems to be about 0.30. All these observations are absolutely consistent with the results of Takahashi et al.

On the other hand, the method of Takahashi et al. reproduces the data trend better; this is not surprising, since the authors developed their formula just to correct the bias of the Goda model observed in Figure 16. However there's still a tendency to underpredict data with $H_{\mathrm{s}} / h \geq 0.3$, which is a very common situation under design conditions. This aspect deserves to be carefully studied in more depth; in the meanwhile, conservative values of the safety factors against sliding and overturning are recommended. An alternative option might be that of using a different calculation method, as described in Section 5.3.

\subsection{The Hiroi Formula}

The main advantage in using Hiroi's approach is that calculations become extremely easy, because the pressure is uniformly distributed along the wall. Figure 16 clearly shows that this formula returns an upper limit (safe value) of the actual pressures, according to the preliminary indications of Vicinanza et al. [20]. The magnitude of the overestimation is on average $33 \%$. However, measures and estimates appear well correlated $\left(R^{2}\right.$ is nearly 0.8$)$ and their relationship is clearly linear. This would indicate that the Hiroi hypothesis of a rectangular pressure distribution is not unrealistic for the present data set.

Figure 16. Measured wave pressures vs. predictions of the Hiroi formula.

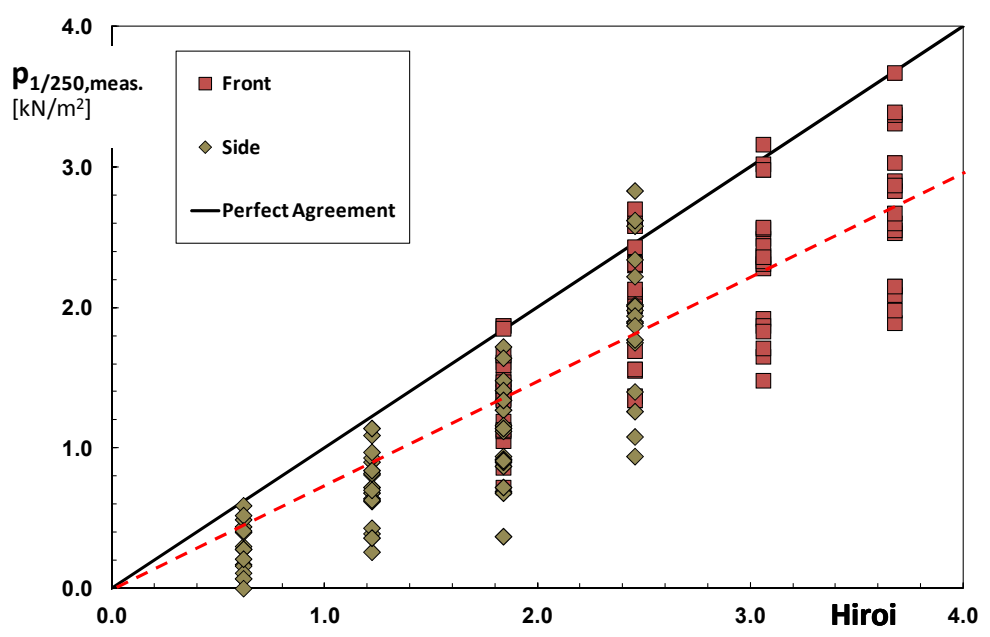

To further investigate this item, the standard deviation of the ratio between predicted and measured wave pressures (at all the transducers) has been calculated for each test. As shown in Figure 17, the Hiroi formula gives the minimum standard error for all the experiments; this supports the idea that the use of a bi-trapezoidal distribution, like that of Goda and Takahashi et al., would not improve the quality of the estimation respect to a simple rectangular one. On contrary it would worsen it. 
Figure 17. Standard deviation of the ratio between measured and calculated $p_{1 / 250}$. Left panel: Front waves; right panel: Side waves.
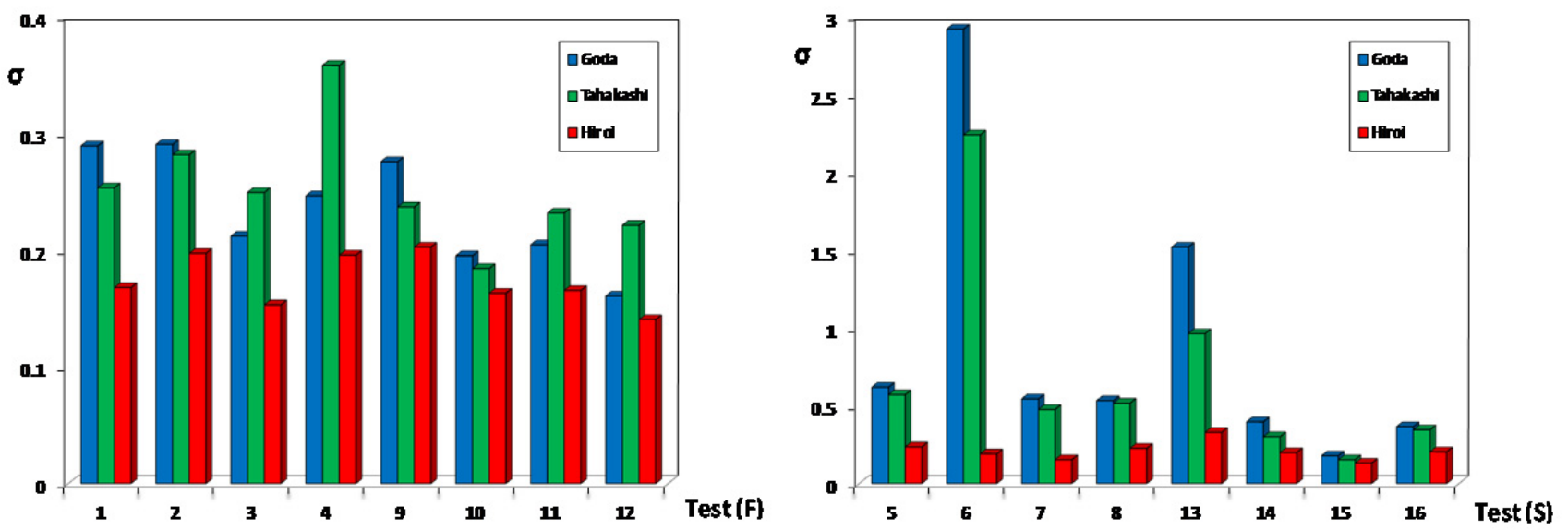

Hence, based on the Hiroi's approach, an alternative calculation method could be proposed, which would have the advantage of simplifying the calculations without any loss of accuracy. Obviously, to build such a design tool it would be necessary to find a relationship between the intensity of the (mean) pressure and the main structural and hydraulic variables. A tentative formula is given in the next paragraph.

\subsection{An Alternative Prediction Method}

The force acting on the structure can be easily calculated using an approach rather similar to that of the Japanese practice for sloping top caissons (paragraph 3.2). It is assumed assumed that the bore which exerts the thrust on the structure is "pushed" forward by the momentum flux, $M_{F}$, of the wave field at the toe of the run-up ramp. Since the momentum flux is conserved, Equation (7) still holds with the sole difference that $M_{F}$ is now derived from the properties of the wave motion at the depth $h$ rather than from the Goda model. The proposed scheme resembles that used by Hughes [21] for calculating the run-up height at smooth slopes.

As $F_{P}$ in Equation (7) represents the maximum force over a wave cycle, $M_{F}$ also has to be seen as the maximum momentum flux in a period $T$ (Hughes, [20]). Hence we have:

$$
M_{F}=\max _{(T)} \int_{-h}^{\eta}\left[p_{d}+\varrho u^{2}\right] d z
$$

where $u$ represents the horizontal component of the wave velocity normal to the structure and $p_{d}$ is the local and instantaneous value of the dynamic pressure associated with the presence of the waves. As already stated, $h$ is the water depth at the toe of the run-up ramp; $\eta$ indicates the elevation of the free surface from the mean sea level.

The simplest way to calculate this momentum flux is by assuming the waves are progressive and linear. Under this assumption, the convective term in $u$ can be neglected as it is at least of order $\mathrm{O}\left(\mathrm{a}^{2}\right)$ and consequently much smaller than the diffusive term in $p$, which is of order $\mathrm{O}(\mathrm{a})$. In this way $M_{F}$ depends only on the contribution of the wave pressure, just like in the Japanese approach. If the sea bottom is flat one gets: 


$$
M_{F}=\rho g \frac{H}{2} \frac{\tanh k h}{k}
$$

in which $H$ is the incident wave height at the toe of the "focuser" and $k$ represents the wave number $2 \pi / L$.

For the application to random waves, it is assumed Equation (13) holds wave by wave; hence under the hypothesis of narrow banded spectrum $\left(H_{1 / 250}=1.8 H_{s}, T_{1 / 250}=T_{p}\right)$ one finally obtains:

$$
F_{P, 250}=\Gamma_{\mathrm{f}} M_{F, 250} \sin \vartheta=\Gamma_{\mathrm{f}} \rho g \frac{1.8 H_{s}}{2} \frac{\tanh \left(k_{p} h\right)}{k_{p}} \sin \vartheta
$$

where the subscript " $p$ " indicates that the wave number is calculated with reference to the peak wavelength. $\Gamma_{f}$ is an empirical coefficient which compensates for all the approximations introduced [this explains the symbol $\cong$ in the Equation (7)]. In particular four aspects deserve to be mentioned:

a. the neglection of wave reflection;

b. the hypothesis of narrow banded waves;

c. the neglection of the phase lag among the pressure transducers when computing the measured force (Section 4.1)

d. the neglection of the convective term in the expression of $M_{\mathrm{F}}$.

The first three points should not produce a correction factor much different from 1. In particular "a" and " $b$ " tend to compensate each other. The wave reflection generally enhances the flux of momentum, as it increases the wave height by $\left(1+K_{R}^{2}\right)^{0.5}$ on averagely on a wave length $\left(K_{R}\right.$ is the reflection coefficient), up to a maximum of $\left(1+K_{R}\right)$ if the structure is located in a pseudo-antinode of the quasi standing wave field; so in principle a multiplier halfway between the previous expressions would be needed to correct Equation (13). On the other hand the finite band of the spectrum tends to reduce $M_{F, 250}$ as $\mathrm{H}_{1 / 250}$ becomes less than $1.8 H_{s}$. As far as the third point is concerned, the difference between the real maximum force and the "envelope force" is expected to be quite small, because, as already stated, the waves are non breaking and accordingly the pressures vary slowly in the time. Thus, a key role is played by the point " $\mathrm{d}$ "; assuming that $p_{d}$ and $\rho u^{2}$ are of the same order of magnitude, it might be concluded that $\Gamma_{f}$ varies be between 1 and 2 . The former value would hold when the hypothesis of linear waves is correct, the latter if $p_{d}$ is nearly equal to $\rho u^{2}$. In this regard, it could be useful to remark that theoretically the convective part of the momentum flux might be easily calculated by using either the Stokes theory or other wave models.

In Figure 18, the measured values of $F_{P 250}$ are compared to $M_{F, 250} \sin \vartheta$ [Equation (14)]. The degree of correlation is excellent and $R^{2}$ exceeds 0.96 . The mean relative error is about $10 \%$ and the estimated value of $\Gamma_{f}$ is about 1.16, which corroborates our previous reasoning. As already mentioned, it is assumed that $F_{P 250}$ is uniformly distributed (in terms of pressures) along the front face of the structure. Apart from the arguments discussed in Section 5.2, it should be noted that actually no alternative distribution law can be deduced from the data. Differently from Hiroi, we make no assumption about the run-up height so that the wave pressure will be always spread over the entire front wall. This is basically for two reasons. On the one hand the situations where the device is not overtopped are generally of no interest for design purposes. On the other hand, whenever they were, no detailed information is available about the actual run-up levels at SSG. 
Figure 18. $F_{P} 250$ vs. $M_{F, 250} \sin \vartheta$.

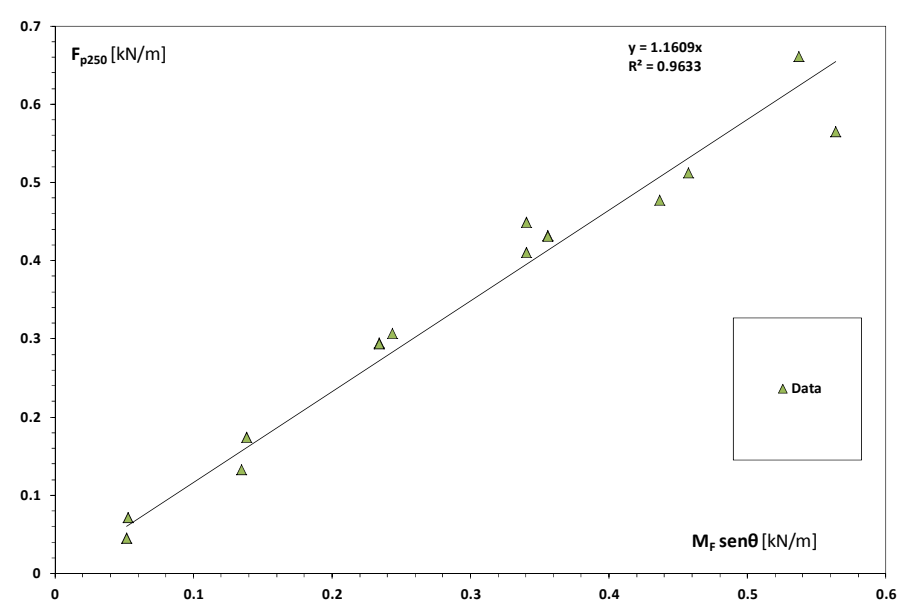

In this frame, the hypothesis of "full" rectangular distribution can be considered acceptable, as it predicts reasonably well the point of application of the thrust in case of significant overtopping (according to Hiroi), whereas it is cautious in absence of overpassing, because the baricentre of loadings is pushed upward, increasing the overturning component of the torque. Figure 19 compares predicted and measured moments; the agreement is rather satisfactory and the relative error rarely surpasses $10 \%$.

Before concluding this paragraph, another point deserves to be commented. In the new method, no correction factor has been introduced to account for the effect of the wave obliquity. This is consistent with the hypothesis of linearizing the momentum flux, because if it depended primarily on the pressure, the wave direction would have no influence on the resulting thrust. Actually the experimental results shown up to now do not indicate any reason to reject this assumption.

Figure 19. Measured vs. predicted overturning moments.

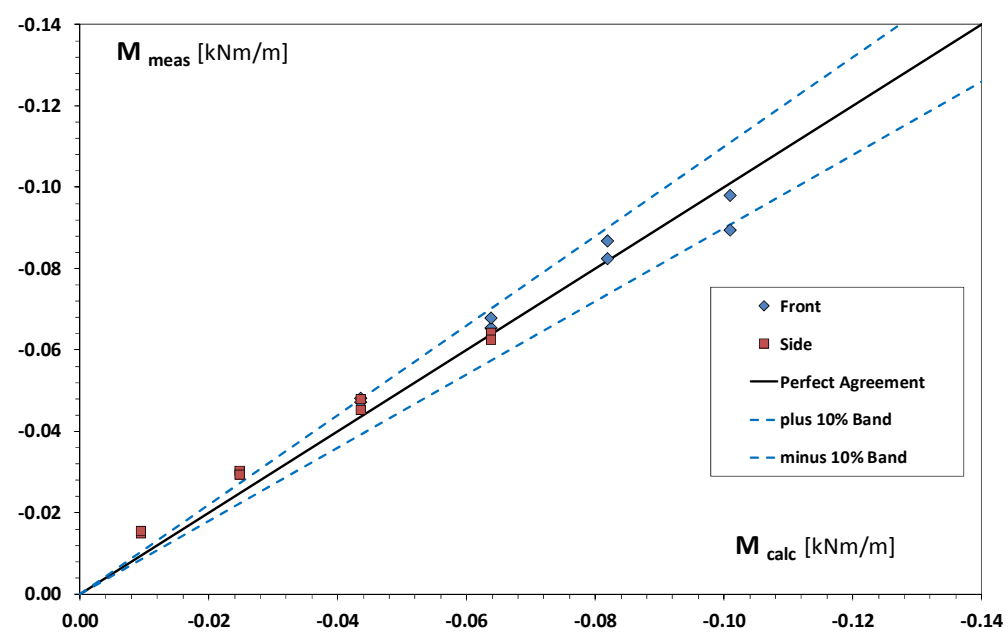

To further investigate this matter, Figure 20 compares the values of the measured pressures (at all the transducers) for couple of tests having the same wave height and period, but different direction. 
Although the data are scattered, the graphs do not provide any reasons to conclude that the pressures exerted by side wave attacks are systematically lower than those exerted by head-on waves. On the contrary, we note that on the upper plate the values of the pressure are larger for oblique waves; Vicinanza and Frigaard [6] reasoned this behavior was related to the occurrence of plunging breakers at the side walls of the structure.

Figure 20. Wave pressures for front and side long crested wave attacks; data refer to couple of tests having the same wave height and period. Top left panel: $H_{s}=0.167 \mathrm{~m}$, $T_{p}=1.81 \mathrm{~s}, h=0.53 \mathrm{~m}$. Top right panel: $H_{s}=0.167 \mathrm{~m}, T_{p}=1.81 \mathrm{~s}, h=0.50 \mathrm{~m}$. Low panel: $H_{s}=0.125 \mathrm{~m}, T_{p}=1.55 \mathrm{~s}, h=0.50 \mathrm{~m}$.

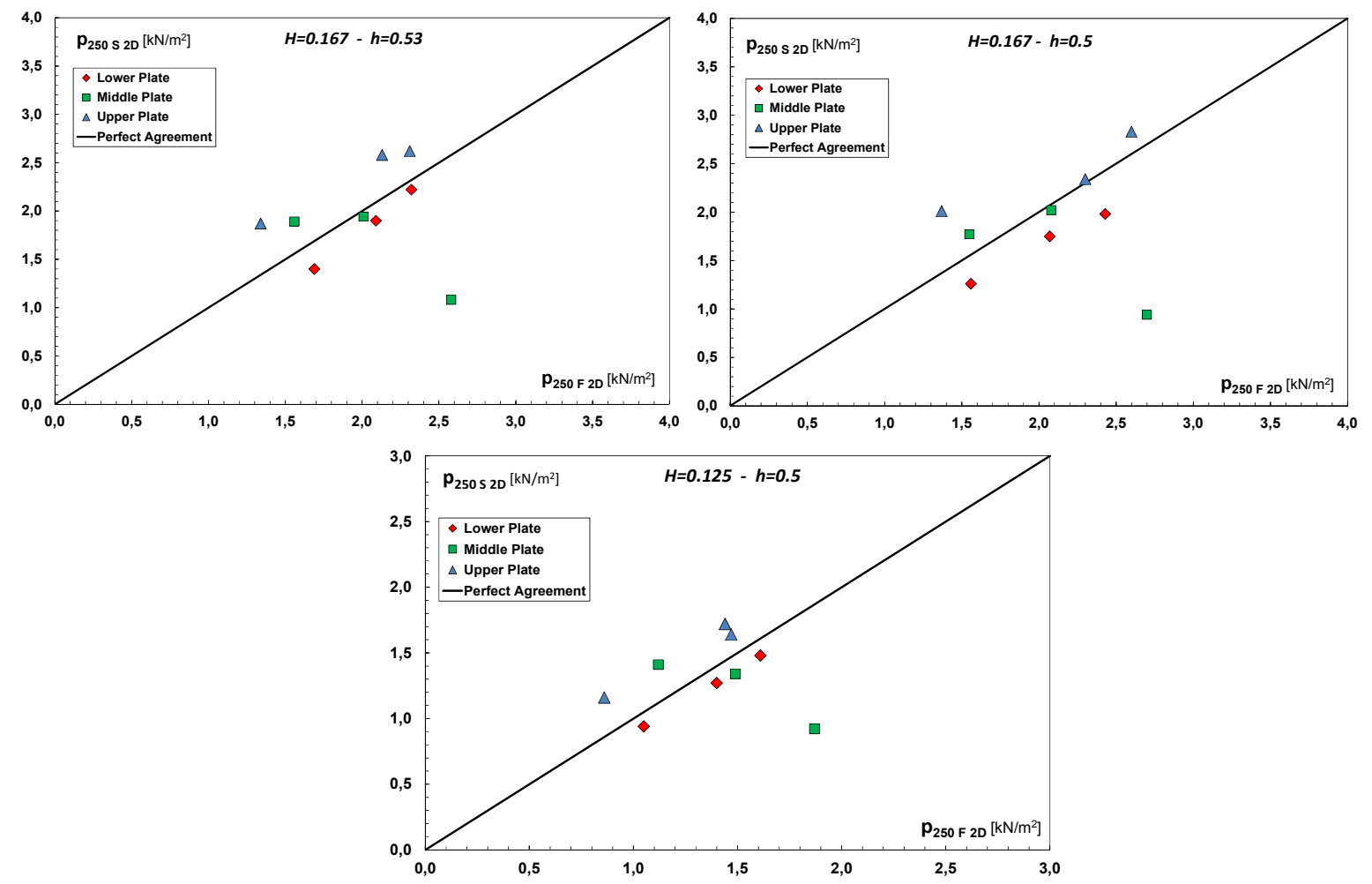

\section{Short Crested Waves}

As mentioned in Section 2, the experiments with short crested waves included 16 sea states, eight with a spreading index $n=4$ (large spreading) and eight with $n=10$ (small spreading). All the tests have been run with a water depth $h=0.53 \mathrm{~m}$; each subarray of eight sea states is made up of four front wave attacks and four side wave attacks. The wave heights and periods are exactly the same as the corresponding $2 \mathrm{D}$ tests, so that the results of the experiments can be easily compared. As shown in Figure 21, the directional dispersion of the wave energy leads to a weak reduction of the mean pressure. This phenomenon seems to be independent of the degree of spreading (Figure 22), whereas the variation of the mean wave direction does not produce any significant effect on the magnitude of loadings (Figure 23), similarly to what observed for the long crested waves. It is very difficult to explain this behavior, which may depend on a number of different factors. On the one hand, the directional spreading might reduce the variance of the wave height distribution in the time domain; this would imply that, for a given $\mathrm{H}_{\mathrm{s}}$, the extreme waves are smaller than in long crested seas. 
Figure 21. Long crested $v s$. short crested waves ( $n=4$, front waves). Top left: $H_{s}=0.125 \mathrm{~m}$, $T_{p}=1.55 \mathrm{~s}$. Top right: $H_{s}=0.167 \mathrm{~m}, T_{p}=1.81 \mathrm{~s}$. Low left: $H_{s}=0.25 \mathrm{~m}, T_{p}=2.07 \mathrm{~s}$. Low right: $H_{s}=0.125 \mathrm{~m}, T_{p}=1.55 \mathrm{~s}$.
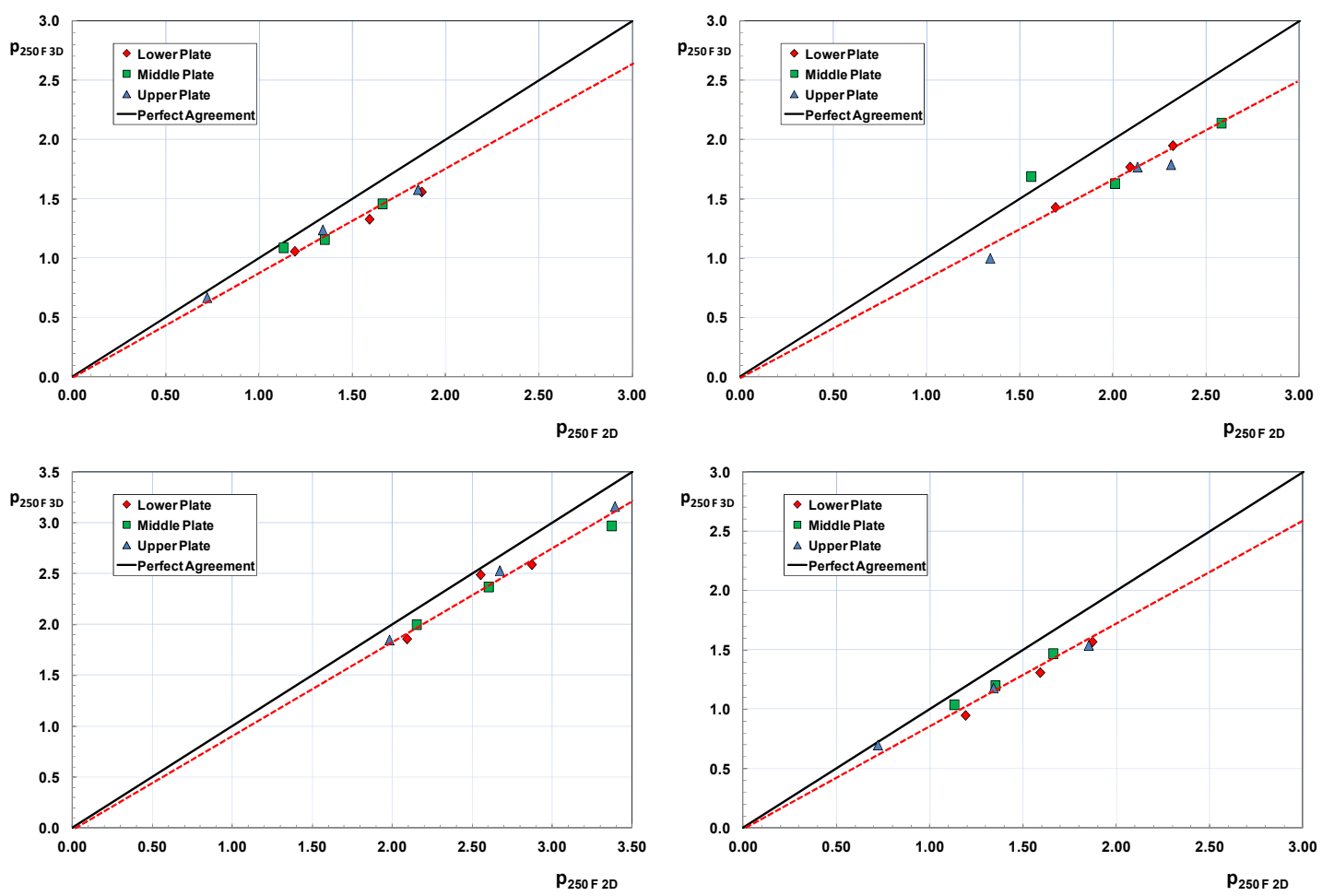

Figure 22. Effect of the spreading index (degree of short-crestedness). Data refer to couple of tests that differ only by the value of $n$ ( $n=10$ in abscissas, $n=4$ in ordinates). Top panels (front waves): left: $H_{s}=0.125 \mathrm{~m}, T_{p}=1.55 \mathrm{~s}$; right: $H_{s}=0.208 \mathrm{~m}, T_{p}=1.94$. Low panels (side waves): left: $H_{s}=0.042 \mathrm{~m}, T_{p}=1.03 \mathrm{~s}$; right: $H_{s}=0.167 \mathrm{~m}, T_{p}=1.81 \mathrm{~s}$.
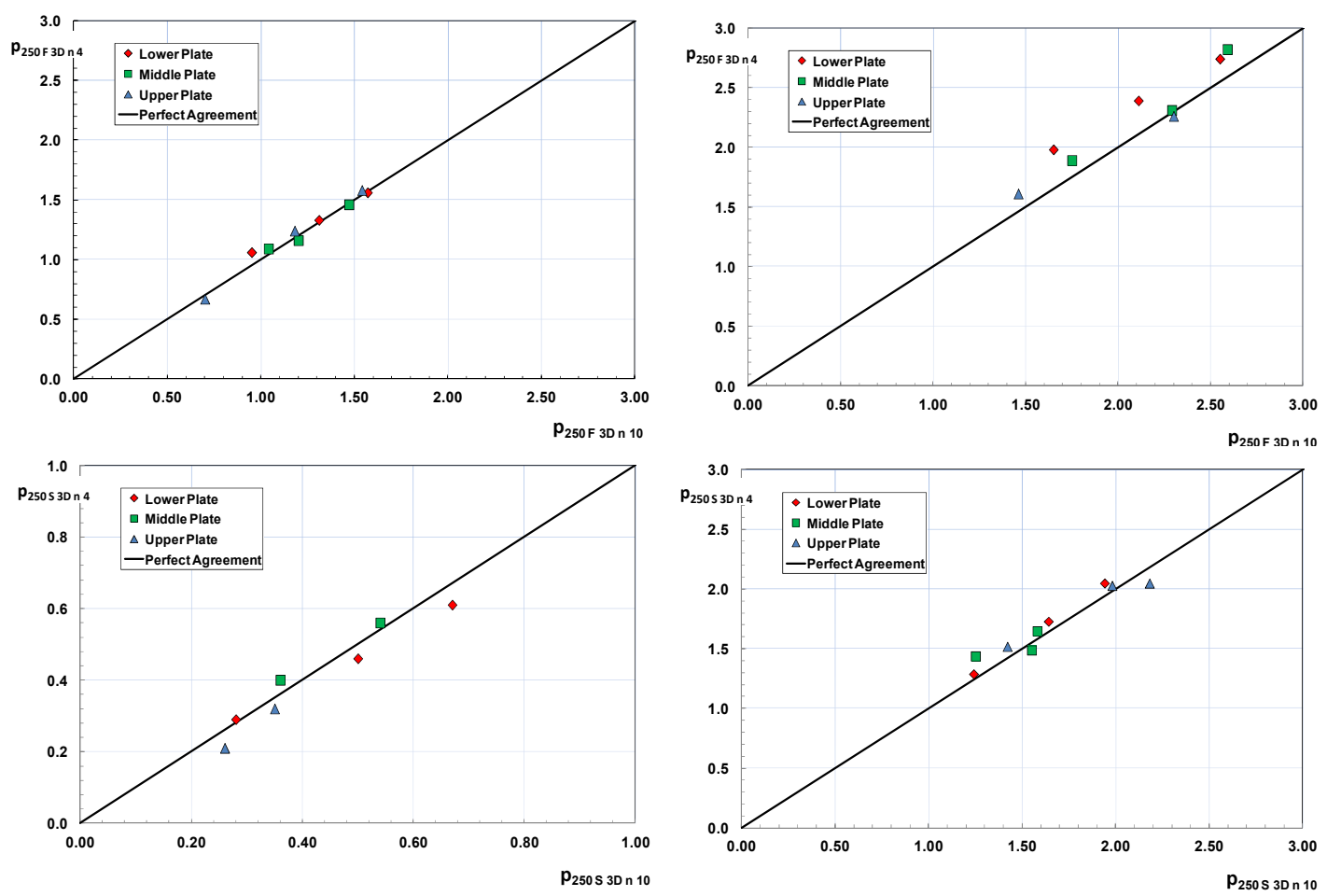
Figure 23. Effect of the mean wave direction on short crested waves. Top left: $H_{s}=0.125 \mathrm{~m}, T_{p}=1.55 \mathrm{~s}, n=4$. Top right: $H_{s}=0.125 \mathrm{~m}, T_{p}=1.55 \mathrm{~s}, n=10$. Low left: $H_{s}=0.167 \mathrm{~m}, T_{p}=1.81 \mathrm{~s}, n=4$. Low right: $H_{s}=0.167 \mathrm{~m}, T_{p}=1.81 \mathrm{~s}, n=10$.
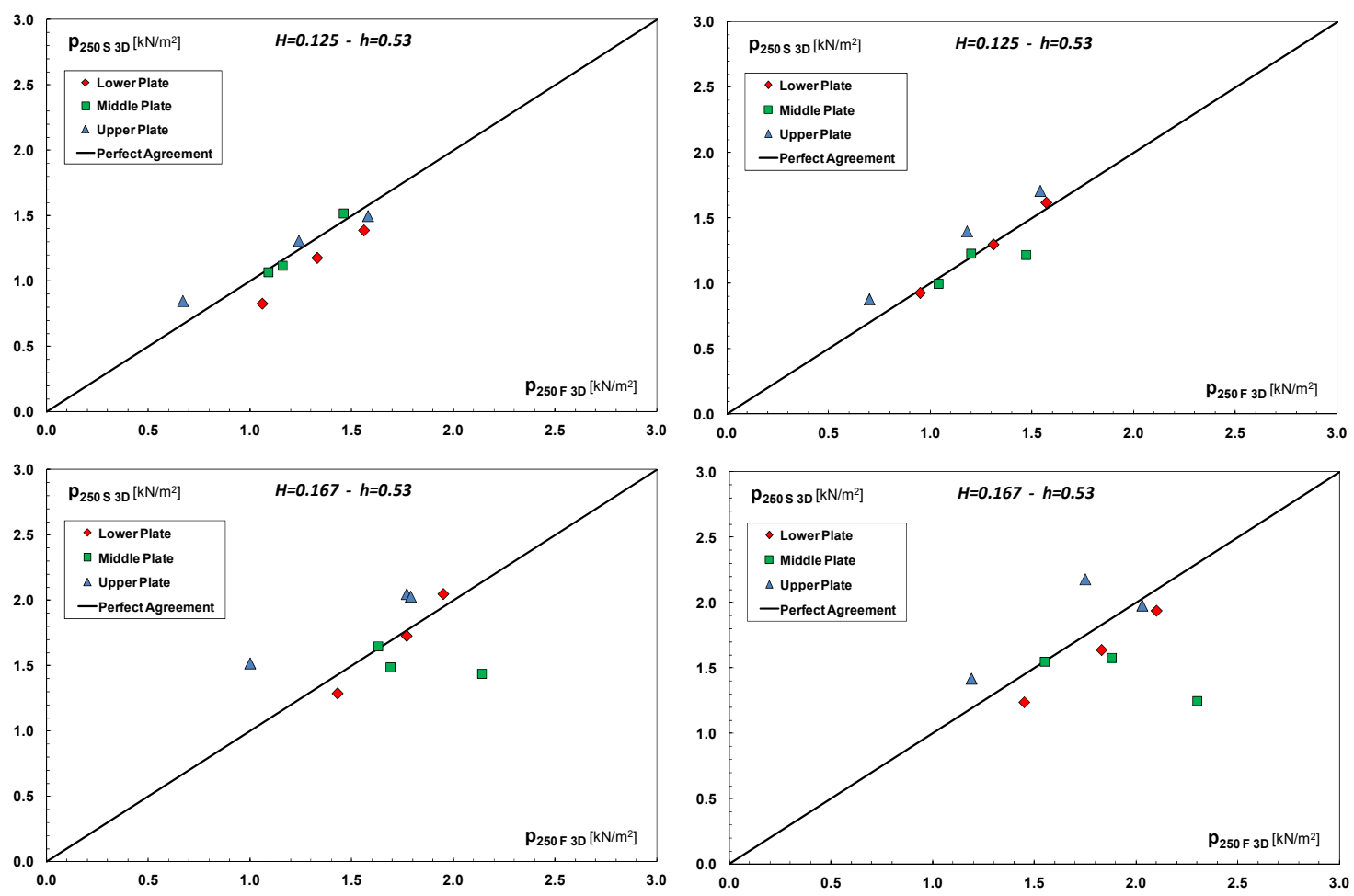

Figure 24. Measured vs. predicted wave forces (short crested waves).

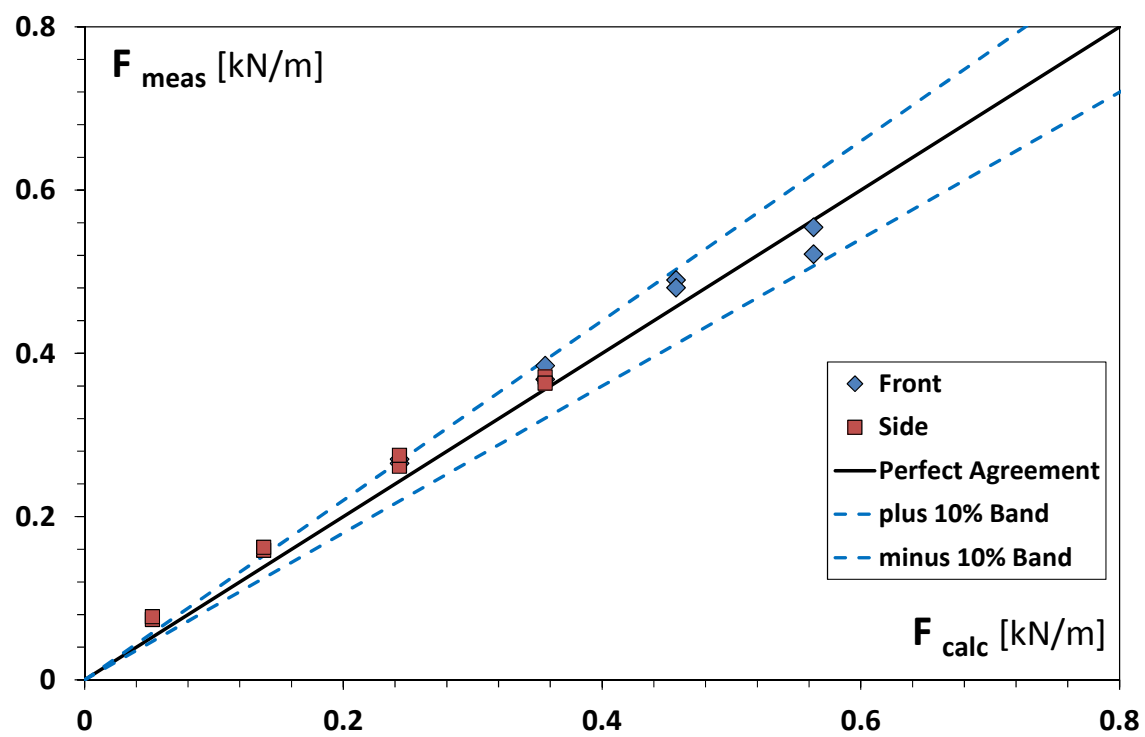

On the other hand, the phase lag among the Fourier components at the same frequency might reduce the pressure which really acts on the water column due, for example, to an increase of the vertical acceleration. At this stage of the research, neither of the above conjectures can be proved and more experiments and analyses are needed to have a deeper insight on these results. However the reduction of the mean pressure implies that the methods described in Section 5.1 are generally conservative for $3 \mathrm{D}$ waves. As far as the new prediction approach is concerned, a decrease of the scale parameter $\Gamma_{f}$ is 
expected. As shown in Figure 24, the mean value of the empirical proportionality factor is now very close to 1 . In the graph, the variables appear still remarkably correlated, being $R^{2}=0.97$. Respect to the case of long crested waves the prediction of the overturning moments is some less efficient, as displayed in Figure 25.

Figure 25. Measured vs. predicted wave overturning moments (short crested waves).

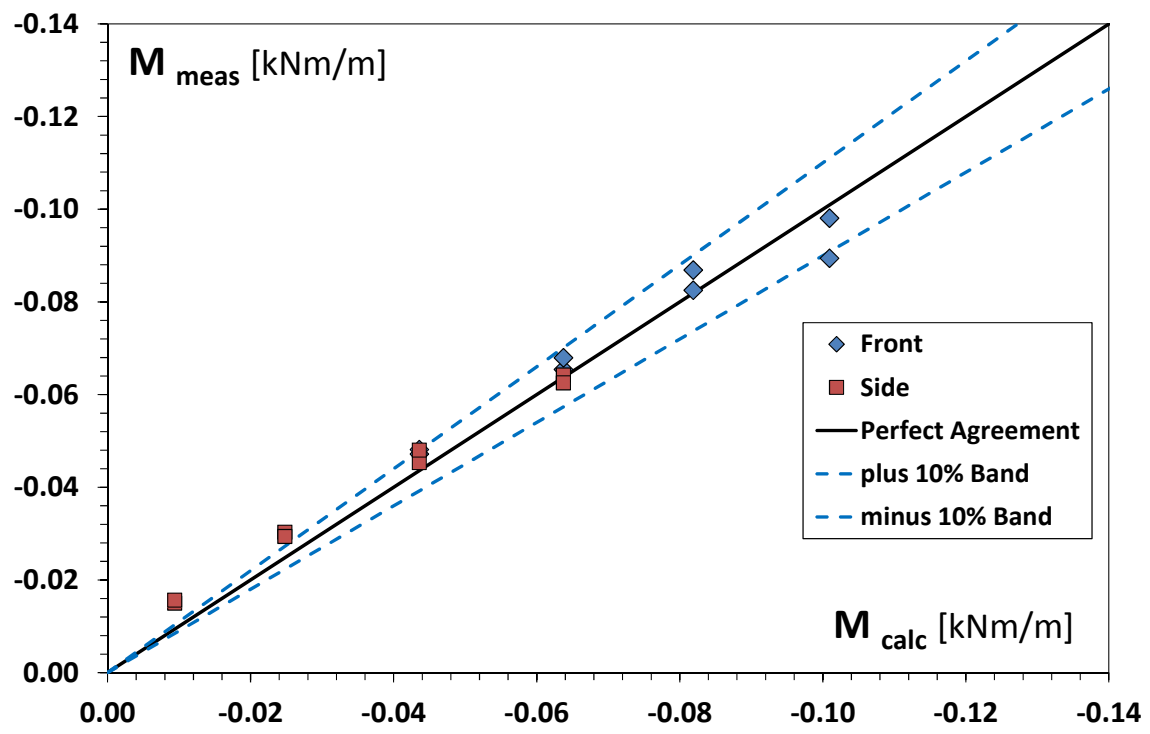

\section{Summary and Conclusions}

In this paper, the random wave experiments of Vicinanza and Frigaard [6] have been re-analyzed, in order to get possible methods for the estimation of the wave force acting onto the front-face of a Seawave Slotcone Generator (SSG). Particular attention has been drawn to the Japanese formulae for the design of monolithic dikes, such as vertical breakwaters, sloping top caissons and trapezoidal walls. It has been found that considering the system "device + run-up ramp" as a sloping wall, the well-known Goda formula gives realistic predictions of the total thrust provided that, as suggested by Tanimoto and Kimura [18], the pressure distribution is rotated from the vertical to the outer face of the structure. This agrees with preliminary results discussed in [20]. However the model seems to underpredict the data with low wave height and to overpredict those with high wave height. This behavior can be corrected by multiplying the pressures by the coefficient $\lambda_{S L}$ [Equation (10)], originally introduced by Takahashi et al. [16] for sloping top caissons. Yet, with this correction, a tendency at slightly underestimate data with wave height to depth ratios larger than 0.3 has been observed; this has to be carefully accounted for in practical applications, when choosing the values of the safety factors against sliding and overturning.

The comparison with the pioneering Hiroi formula proved the latter may be employed as an upper limit estimate of the wave force. However, data also showed that the use of a rectangular pressure distribution, beside simplifying calculations compared to the bi-trapezoidal hypothesis of the Goda method, produces less scatter between measured and predicted pressures.

In general, the fact that the traditional formulae of the maritime engineering fit only partially the case of the SSG is not surprising. In this regard one should mind that coastal engineers generally tend 
to minimize the wave overtopping occurrence, whilst SSG uses a steep cliff just to enhance it. Then the design concepts of breakwaters and SSGs must be significantly different.

In the last part of the paper, a new prediction method has been presented, which proved to perform remarkably well with respect to the present data set. It is based on the momentum flux principle which, originally proposed by Hughes [21] for the prediction of the run-up height at smooth slopes, resulted effective in a number of relevant phenomena of the coastal engineering [22]. The degree of correlation with the data (always larger than 0.95) seems to indicate that the relationships with all the hydraulic variables are well described. According to the findings discussed above, the estimated wave force has been assumed to be uniformly distributed along the front plates. In spite of this simplification, good predictions of the overturning moments have been obtained. This seems to indicate that although the actual pressure distribution follows a complicated path, its centre of mass lies about halfway up the structure height. However, new experiments are needed to confirm present results.

As a last but not least remark, it should be noted that all the prediction methods discussed in this work can be used to calculate the resulting loads (force and moment), but not for estimating the pressures which locally act onto the front plates. Indeed the latter is important when addressing the problem of determining the thickness of the single concrete plate and the amount of steel to be used. This aspect will be specifically handled in a next paper. In the meanwhile, the pressure given by the Hiroi formula may serve this scope (Figure 18). In this regard it is useful to remark that the maximum underprediction (unsafe prediction) detected from the data is equal to $14 \%$.

In conclusion, the estimation methods here proposed can be viewed as generally reliable for practical purposes. This is despite a number of simplified assumptions, among which the fact of applying results of mostly bi-dimensional model tests (i.e., the Goda and Takahshi formulae) to fully 3D experiments, where the structure width is rather small compared to the extension of the wave front. In this regard it should be noted this approach is generally conservative as it has long been recognized that under oblique seas, the lack of wave coherence along the wall produces a reduction of the mean peak force [23-25]. However this aspect might concern the Japanese empirical formulae, while the momentum flux approach is supposed to apply to 3D situations as long as the hypothesis of neglecting the convective term is realistic. On the other hand, the effect of the short crestedness on long structures appears somewhat less clear (e.g. [26]) and deserves to be studied in depth in the future research.

\section{Acknowledgments}

The authors wish to gratefully acknowledge Jens Peter Kofoed as well as an anonymous reviewer for their fruitful contribution in improving the quality of this paper.

\section{References}

1. SSG Papers. Available online: http://vbn.aau.dk/da/publications/searchall.html?searchall=ssg (accessed on 24 January 2006).

2. Kofoed, J.P. Wave Overtopping of Marine Structures-Utilization of Wave Energy. Ph. D. Thesis, Aalborg University, Aalborg, Denmark, 2002. 
3. Kofoed, J.P. Model testing of the wave energy converter Seawave Slot-Cone Generator. In Hydraulics and Coastal Engineering (No. 18), Department of Civil Engineering, Aalborg University: Aalborg, Denmark, 2005;

4. Margheritini, L.; Vicinanza, D.; Frigaard, P. SSG wave energy converter: design, reliability and hydraulic performance of an innovative overtopping device. J. Renew. Energy 2009, 34, 1371-1380.

5. Vicinanza, D.; Margheritini, L.; Kofoed, J.P.; Buccino, M. The SSG wave energy converter: Performance, Status and Recent Developments. Energies 2012, 5, 193-226.

6. Vicinanza, D.; Frigaard, P. Wave pressure acting on a seawave slot-cone generator. Coast. Eng. 2008, 55, 553-568.

7. Hughes, S.A. Physical Models and Laboratory Techniques in Coastal Engineering; World Scientific Publishing: Singapore, 1993.

8. Le Mèhautè, B. Similitude in Coastal Engineering. In Journal of Waterways, Harbors and Coastal Division, Proceedings of the American Society of Civil Engineers; American Society of Civil Engineers (ASCE): New York, NY, USA; 1976, Volume 102 (WW3), pp. 317-335.

9. EurOTop: Wave Overtopping of Sea Defences and Related Structures: Assessment Manual. EA Environment Agency: Bristol, UK, August 2007. Available online: http://www.kennisbankwaterbouw.nl/DesignCodes/EurOtop.pdf (accessed on 16 November 2012).

10. Cuomo, G.; Allsop, N.H.W.; Takahashi, S. Scaling of wave impact pressures on vertical walls. Coast. Eng. 2010, 57, 604-609.

11. Kofoed, J.P. Vertical Distribution of Wave Overtopping for Design of Multi Level Overtopping Based Wave Energy Converters. In Proceedings of the 30th International Conference on Coastal Engineering, San Diego, CA, USA, 3-8 September 2006.

12. Van der Meer, J.W.; Janssen, J.P.F.M. Wave Run up and Wave Overtopping at Dikes; Technical Report, Task Committee Reports: Delft, The Netherlands, 2005.

13. Franco, L.; de Gerloni, M; van der Meer, J.W. Wave overtopping on vertical and composite breakwaters. In Proceedings of the 24th International Conference on Coastal Engineering, Kobe, Japan, 23-28 October 1994.

14. Goda, Y. Japan's design practice in assessing wave forces on vertical breakwaters. In Wave Forces on Inclined and Vertical Wall Structures; American Society of Civil Engineers (ASCE): New York, NY, USA, 1995; p. 402.

15. Takahashi, S.; Tanimoto, K.; Simosako, K. A proposal of impulsive pressure coefficient for design of composite breakwaters. In Proceedings of International Conference on Hydro-Technical Engineering for Port and Harbor Construction; Port and Harbour Research Institute: Yokosuka, Japan, 1994.

16. Takahashi, S.; Hosoyamada, S.; Yamamoto, S. Hydrodynamic characteristics of sloping top caissions. In Proceedings of International Conference on Hydro-Technical Engineering for Port and Harbour Construction; Port and Harbour Research Institute: Yokosuka, Japan, 1994.

17. Morihira, M.; Kunita, O. Model experiments on hydraulic characteristics of sloped wall breakwater. Coast. Eng. Japan 1979, 26, 288-295.

18. Tanimoto, K.; Kimura, K. A Hydraulic Experiment Study on Trapezoidal Caisson Breakwaters; Technical Note N.528; Port and Harbour Research Institute: Yokosuka, Japan, 1985. 
19. Goda, Y. Random Seas and Engineering Applications; University of Tokyo Press: Tokyo, Japan, 1986.

20. Vicinanza, D.; Ciardulli, F.; Buccino, M.; Calabrese, M.; Kofoed, J.P. Wave loadings acting on an innovative breakwater for energy production. J. Coast. Res. 2011, 64, 608-612.

21. Hughes, S.A. Estimation of wave run-up on smooth, impermeable slopes using the wave momentum flux parameter. Coast. Eng. 2004, 51, 1085-1104.

22. Vicinanza, D.; Caceres, I.; Buccino, M.; Gironella, X.; Calabrese, M. Wave disturbance behind low-crested structures: Diffraction and overtopping effects. Coast. Eng. 2009, 56, 1176-1185.

23. Battjes, J.A. Effects of short-crestedness on wave loads on long structures. J. Appl. Coast. Res. 1982, 4, 165-172.

24. Allsop, N.W.H.; Calabrese, M. Impact loadings on vertical walls in directional seas. In Proceedings of the 26th International Conference on Coastal Engineering, Copenhagen, Denmark, 22-26 June 1998; Volume 2, pp. 2056-2068.

25. Calabrese, M.; Allsop, N.W.H.; Buccino, M. Effect of Random Multidirectional Wave Fields on Wave Loads on Vertical and Composite Breakwaters. In Proceedings of the 27th International Conference on Coastal Engineering, Sydney, Australia, 16-21 July 2000; Volume 2, pp. 1710-1723.

26. Boccotti, P. Wave Mechanics for Ocean Engineering; Elsevier Oceanography Series: Amsterdam, The Netherlands, 2000.

(C) 2012 by the authors; licensee MDPI, Basel, Switzerland. This article is an open access article distributed under the terms and conditions of the Creative Commons Attribution license (http://creativecommons.org/licenses/by/3.0/). 